\title{
Credit Constraints, Quality, and Export Prices: Theory and Evidence from China *
}

\author{
Haichao Fan ${ }^{\dagger} \quad$ Edwin L.-C. Lai ${ }^{\ddagger} \quad$ Yao Amber Li ${ }^{\S}$ \\ The Hong Kong University of Science and Technology \\ First Draft: February 2012 \\ This Version: December 2012
}

\begin{abstract}
This paper examines the relationship between the credit constraints faced by a firm and the unit value prices of its exports. The paper modifies Arkolakis's (2010) model of trade with heterogeneous firms by introducing endogenous quality and credit constraints. The model predicts that tighter credit constraints faced by a firm reduce its optimal prices as its choice of lower-quality products dominates the price distortion effect resulting from credit constraints. However, a competing theory based on the alternative assumption that quality is exogenous across firms would predict completely opposite results: Prices increase as firms face tighter credit constraints. An empirical analysis using Chinese bank loans data, Chinese firm-level data from the National Bureau of Statistics of China (NBSC), and Chinese customs data strongly supports the predictions of the endogenous-quality model. Moreover, the predictions of the exogenous-quality model are supported by using quality-adjusted prices in regression analysis. In addition, we confirm the mechanism of quality adjustment: firms optimally choose to produce lower-quality products when facing tighter credit constraints.
\end{abstract}

JEL: F1, F3, D2, G2, L1

Keywords: credit constraints, credit access, credit needs, endogenous quality, export prices, quality, heterogeneous firms, productivity

\footnotetext{
${ }^{*}$ We thank Gene Grossman, Robert Staiger, Shang-Jin Wei, Stephen Yeaple, Kalina Manova, Mark Roberts, Norman Loayza, Davin Chor, Jonathan Vogel, Jim MacGee, Heiwai Tang, Loretta Fung, Yi Lu, Kenneth Corts, Pengfei Wang, David Cook, Albert Park, Xi Li, Nelson Mark, Zhigang Tao, Larry Qiu, Wen Zhou, Zhanar Akhmetova, Wei Liao, Peng Wang, the participants of the Midwest International Trade Conference (Indiana University Bloomington, May 2012), the Asia Pacific Trade Seminars Annual Meeting (Singapore Management University, July 2012), the Workshop on Emerging Economies (University of New South Wales, August 2012), the 2nd China Trade Research Group Annual Conference (Shandong University, China, May 2012), the 7th Biennial Conference of Hong Kong Economic Association (Lingnan University, HK, December 2012), and of seminars held at HKUST, University of Hong Kong, University of Western Ontario, Hong Kong Institute for Monetary Research, Shanghai University of Finance and Economics, Fudan University, Shanghai Jiaotong University, Zhejiang University, and Lingnan College at Sun Yat-sen University for helpful discussions. An earlier version of this paper was circulated with the title "Credit Constraints and Export Prices: Theory and Evidence from China". All remaining errors are our own.

${ }^{\dagger}$ Fan: Department of Economics, The Hong Kong University of Science and Technology. Email: fhxac@ust.hk.

${ }^{\ddagger}$ Lai: Department of Economics, The Hong Kong University of Science and Technology. Email: elai@ust.hk. CESifo Research Network Fellow.

${ }^{\S} \mathrm{Li}$ : Corresponding author. Department of Economics, The Hong Kong University of Science and Technology, Clear Water Bay, Kowloon, Hong Kong SAR-PRC. Email: yaoli@ust.hk. URL: ihome.ust.hk/ yaoli. Tel: (852)2358 7605 ; Fax: (852)2358 2084. Research Affiliate of the China Research and Policy Group, Western-CIGI-China-Ontario Project.
} 


\section{Introduction}

There is a growing body of literature on the effects of credit constraints on international trade, especially after the financial crisis of 2008. Most prior studies have focused on either explaining the mechanism of why exporters need more credit than domestic producers (e.g., Amiti and Weinstein, 2011; Feenstra et al., 2011), or the consequences of different credit conditions on firm entry into exporting, exporters' sales, or multinational activities (Manova, forthcoming; Manova et al., 2011; Chor and Manova, 2012; Minetti and Zhu, 2011, among others). However, to the best of our knowledge, the impacts of credit constraints on a firm's choice of optimal quality and optimal price have not been explored. This paper fills a gap in the literature by linking credit constraints to firm attributes and action such as its productivity and its choice of product quality and optimal prices.

Understanding the mechanism through which credit constraints affect export prices helps us better understand how credit constraints affect a firm's exporting behavior via optimal choice of quality and pricing. In particular, it helps to explain the differential impacts of credit constraints on the intensive margin of trade across products through their effects on the unit value prices of different products. As the intensive margin of a product is measured by the total value of its exports, the change in the intensive margin is affected by two factors: the change in the quantity exported, and the change in the unit value price of the exported product. Therefore, a thorough analysis on the effect of credit constraints on unit value prices can help us better understand their effect on the intensive margin of trade. Moreover, credit constraints affect bank loans to firms, which are used to cover upfront costs. Tighter credit constraints would affect upfront costs and therefore distort a firm's choice of optimal price more than before. As noted in the literature on financial distress, binding credit constraints may cause firms to act in ways that would be suboptimal in normal times, which may lead them to produce lower-quality products, which in turn lowers the unit value price of the product (Phillips and Sertsios, 2011). However, how and why credit constraints affect the export prices of different products differently has not been studied thoroughly. Our paper tries to fill this gap in the literature.

To study the impacts of credit constraints on export prices, we modify the heterogenous-firm trade model proposed by Arkolakis (2010). Our model differs from his in two aspects. The first is that we embed endogenous quality in our model. According to the quality-and-trade literature, more productive firms tend to produce higher-quality products, which yield higher export prices. ${ }^{1}$ The observed relationship between prices and productivity depends on two opposing forces: the quality adjustment effect (i.e., higher-productivity firms charge higher prices via selling higherquality products) and the productivity effect (i.e, higher-productivity firms are able to set lower prices via having lower marginal cost when keeping quality unchanged). Given certain plausible

\footnotetext{
${ }^{1}$ See Verhoogen (2008), Kugler and Verhoogen (forthcoming), Hallak (2010), Hallak and Sivadasan (2011), Gervais (2011), Johnson (2012), Manova and Zhang (forthcoming), Antoniades (2012), among others.
} 
parametric values, it can be shown that the quality adjustment effect dominates, and a firm's optimal price is positively correlated with its productivity.

Our second distinction from Arkolakis (2010) is our introduction of credit constraints, which act through two channels. First, we assume that firms must externally finance a certain fraction of its total costs, including variable costs and fixed costs, in order to produce as well as to enter foreign markets. This fraction captures the credit needs of the firm. The higher is this fraction, the more likely the firm faces binding credit constraints. Second, we assume that due to frictions in the financial markets, a firm cannot borrow more than a certain fraction of its expected cash flow. This fraction of a firm's expected cash flow capture the firm's credit access. To sum up, a firm is more likely to have tighter credit constraints if it has a higher level of "credit needs" or faces a lower level of "credit access".

The theory indicates that the impacts of credit constraints on prices depend on two opposing forces: (i) the quality adjustment effect, which lowers product quality and therefore reduces prices when credit constraints are more stringent; (ii) the price distortion effect, which increases price when credit constraints are tighter. It should be noted that the price distortion effect is independent of the assumption of endogenous quality. The intuition behind the price distortion effect is as follows. Given product quality, a firm facing tighter credit constraints will reduce its output, leading to excess demand for its product at the initial price level, which in turn pushes up its price. We call this effect the price distortion effect. When product quality is endogenously chosen by a firm, the quality adjustment effect dominates the price distortion effect, and therefore optimal prices fall when firms face tighter credit constraints. On the contrary, if product quality was exogenously fixed across firms, we show that the outcome would be exactly opposite: the existence of more stringent credit constraints would raise optimal prices due to the price distortion effect resulting from credit constraints.

Next, we test our model using a matched Chinese firm-product level dataset, based on Chinese firm-level production data from the National Bureau of Statistics of China (NBSC) and Chinese customs data at the transaction-product level. The unique advantage of this matched database is that it contains information on unit value prices of exports at the product-firm level as well as the information needed to measure credit constraints and firm productivity. To measure the severity of credit constraints via credit needs faced by firms, we first follow Manova et al. (2011) to employ four different measures at the industry level: external finance dependence, R\&D intensity, inventory-to-sales ratio, and asset tangibility. We use US data for those measures as they are widely used in cross-country studies in the literature. For robustness, we also follow Rajan and Zingales (1998) and Manova (forthcoming) to calculate external finance dependence using Chinese firm-level data. To proxy for credit access, we collect balances of bank credits, long-term bank loans and short-term bank loans by province (normalized by province GDP) in China to reflect the credit access by firms located in different regions. In addition, we compare different types of firm 
ownership in China as each type is expected to be associated with a different level of credit access. Finally, to compute productivity, we use the augmented Olley and Pakes's (1996) approach, which alleviates simultaneity bias and selection bias, to estimate a firm's total factor productivity. In the robustness checks, we also report results with labor productivity measured by the value added per employee and the results with the TFP computed by the augmented approach of Ackerberg et al. (2006) devised by De Loecker and Warzynski (2012).

We test the empirical implications of our model using a model-based estimation equation. All empirical results strongly support the theoretical predictions of the endogenous-quality model: First, there exists a significant, robust, and positive relationship between export prices and firm productivity. Second, tighter credit constraints (i.e., either a higher level of credit needs or a lower level of credit access) significantly reduce the price charged by the firm. Third, when a firm faces more stringent credit constraints, it produces lower-quality products.

We verify the quality-adjustment mechanism through three exercises. First, we estimate qualityadjusted prices by adopting Khandelwal et al.'s (2011) method, in which quality-adjusted price is defined as observed price less estimated quality. We then replicate the regressions with qualityadjusted prices as dependent variable. As expected, once prices are adjusted for quality, the predictions of the exogenous-quality model are obtained: tighter credit constraints indeed raise export prices; more productive firms set lower prices; the positive effects of credit access on prices are attenuated, and, sometimes, become significantly negative. Second, we compare two sets of regressions, namely, with and without controlling for (labor) input quality, such as average wage of workers and the share of college workers in total employment. We find that without controlling for labor input quality, the observed effects of credit constraints and productivity on export prices will be amplified. Third, we compare the results based on a set of products with higher variation in product quality and those based on another set of products with lower variation in product quality. We find that firms producing products associated with higher quality variation are more affected by credit constraints and the observed product prices are more in line with the predictions of the endogenous-quality model. In other words, the magnitudes of the predicted effects of credit constraints on prices are larger for the observations with more variation of quality, thus validating the mechanism of quality adjustment in our endogenous-quality model. Overall, our empirical results demonstrate that the endogenous-quality model performs well in explaining firms' pricing behavior under credit constraints. Without the mechanism of quality adjustment that we propose, it is hard to rationalize the observed impacts of credit constraints on a firm's export prices.

The main contribution of this paper is that it offers both a theory and the empirical evidence on the impacts of credit constraints on product quality and export prices, adding to the emerging literature on the role of financial constraints in international trade. To the best of our knowledge, this paper provides the first compelling analysis of the impacts of credit constraints on export prices under a heterogeneous-firm framework. This paper also complements the large quality-and-trade 
literature in confirming the prevalence of product quality heterogeneity at the firm level and explaining the mechanism of quality adjustment. Our finding of a positive relationship between export prices and firm productivity is consistent with the findings in the literature on product quality (e.g., Verhoogen, 2008; Kugler and Verhoogen, forthcoming; Hallak, 2010; Johnson, 2012; and Hallak and Sivadasan, 2011).

The remainder of the paper is organized as follows. Section 2 presents a trade model with heterogeneous firms, featuring endogenous product quality and credit constraints to illustrate the impact of credit constraints on the optimal prices of exports. Section 3 describes the data and introduces the strategy of the empirical analysis. Section 4 presents the empirical results and Section 5 provides some robustness checks. Section 6 concludes.

\section{A Model of Credit Constraints, Product Quality, and Export Prices}

In this section we present a partial equilibrium model to study the behavior of the unit value export prices across firms that compete for the same product-destination market. The model modifies the heterogeneous-firm trade model proposed by Arkolakis (2010), by incorporating endogenous quality and credit constraints in the analysis. Goods are differentiated, and each good is produced by one firm. The main departure from the existing literature is that firms are heterogeneous in both their productivity and the degree of credit constraints they face. Firms choose not only the optimal price but also the optimal product quality as well as the optimal volume of advertisement.

\subsection{Preferences and the Market Structure}

We denote the source country by $i$ and the destination country by $j$, where $i, j \in 1, \ldots, N$. Country $j$ is populated by a continuum of consumers of measure $L_{j}$. Consumers in country $j$ have access to a set of goods $\Omega_{j}$, which is potentially different across countries. In each source country $i$, there is a continuum of firms that ex ante differ in their productivity level, $\phi$, the degree of credit access, $\theta$, and the credit needs, $d$. A firm facing higher $\theta$ has more credit access; a firm with higher $d$ has greater credit needs. A lower level of $\theta$ or a higher level of $d$ implies tighter credit constraints for this firm (see Section 2.2. for more detail). We assume that a representative consumer in country $j$ has a constant-elasticity-of-substitution (CES) utility function given by:

$$
U_{j}=\left(\int_{\omega \in \Omega_{j}}\left[h_{i j}\left(q_{i j}(\omega), a_{i j}(\omega)\right) x_{i j}(\omega)\right]^{\frac{\sigma-1}{\sigma}} d \omega\right)^{\frac{\sigma}{\sigma-1}}
$$

where $h_{i j}\left(q_{i j}, a_{i j}\right)$ is a demand shifter with $q_{i j}(\omega)$ being the quality of variety $\omega$ originated from country $i$ and $a_{i j}(\omega)$ being the amount of advertisement for this good; $x_{i j}(\omega)$ is country $j^{\prime}$ s quan- 
tity consumed of variety $\omega$ originated from country $i$; and $\sigma>1$ is the elasticity of substitution between varieties. We assume for simplicity that $h_{i j}\left(q_{i j}, a_{i j}\right)=q_{i j}(\omega) a_{i j}(\omega)$. Therefore, consumer optimization yields the following demand function for variety $\omega$ :

$$
x_{i j}(\omega)=\left[q_{i j}(\omega) a_{i j}(\omega)\right]^{\sigma-1} \frac{\left[p_{i j}(\omega)\right]^{-\sigma}}{P_{j}^{1-\sigma}} Y_{j}
$$

where $p_{i j}(\omega)$ is the price of variety $\omega, P_{j}=\left(\int_{\omega \in \Omega_{j}}\left[p_{i j}(\omega) /\left(q_{i j}(\omega) a_{i j}(\omega)\right)\right]^{1-\sigma} d \omega\right)^{\frac{1}{1-\sigma}}$ is an aggregate price index (adjusted by the demand shifter), and $Y_{j}$ represents the total expenditure of country $j$. Given the same price, higher-quality products and more heavily-advertised products generate a larger demand.

\subsection{The Firm's Problem}

A firm's technology is captured by a cost function that features, for any given quality, a constant marginal cost with a fixed overhead cost. Labor is the only factor of production. Following convention, we assume that there is an iceberg trade cost such that $\tau_{i j} \geq 1$ units of good must be shipped from country $i$ in order for one unit to arrive in $j$. Firms face no trade costs in selling in its home market, i.e., $\tau_{i i}=1$. To simplify notation, the subscripts for source and destination as well as the index for variety are suppressed hereafter. In addition, the wage rate of the source country is normalized to one.

Following the recent quality-and-trade literature, we assume that there is a positive relationship between quality and marginal cost of production. The rationale is that a higher marginal cost is required to produce a higher-quality product. The positive relationship between quality and marginal cost is common to the recent quality-and-trade literature, including Baldwin and Harrigan (2011), Verhoogen (2008), and Johnson (2012). In this paper, the marginal cost of production is assumed to be $q^{\alpha} / \phi$, where $\alpha \in(0,1)$. Hence, the marginal cost increases in quality $q$, and $\alpha$ captures the elasticity of marginal cost with respect to quality.

Firms face two types of fixed costs: the fixed cost of marketing and the fixed costs of production. The fixed cost of marketing, denoted by $f(a)$, is assumed to be equal to $f_{x} \frac{a^{1+\epsilon}}{1+\epsilon}$, where the amount of advertising $a \in[0,+\infty), \epsilon>0$, and $f_{x}$ is a constant. ${ }^{2}$ The modeling of advertising technology draws upon the work of Butters (1977), Grossman and Shapiro (1984), Stegeman (1991), and Dinlersoz and Yorukoglu (2008). $f(a)$ is exogenously given and common to all firms. The formula of the advertising technology captures the fact, established by Sutton (2007), that the effectiveness of advertising is subject to diminishing returns. The fixed cost of production is assumed to be equal to $f_{d} q^{\beta}(\beta>0)$. It represents the fixed investments in production associated

\footnotetext{
${ }^{2}$ Here advertising is merely a representative channel of marketing. Any other form of fixed marketing cost is also included in $f(a)$, which we view as penetration costs to enter foreign markets.
} 
with quality improvement (e.g., R\&D expenditures to improve the product quality or costs of employing higher-quality inputs), where $f_{d}$ is a constant and $1 / \beta$ measures the effectiveness of fixed investment in raising quality.

We posit that all firms are subject to possible liquidity constraints in paying all types of costs. Like the extended model in Manova (forthcoming), we assume that exporters need to raise outside capital for a fraction $d \in(0,1)$ of all costs associated with foreign sales, including variable costs and the two types of fixed costs mentioned above. ${ }^{3}$ This fraction $d$ represents the financial needs of a firm. The higher the financial needs, the higher is $d$, and we call this fraction $d$ the "credit needs" parameter. We also assume that, constrained by the level of financial development, firms cannot borrow more than a fraction $\theta$ of the expected cash flow from exporting. If $\theta$ is higher, firms can borrow more from external finance (mainly through bank loans). Therefore, $\theta$ is referred to as the credit access by firms. A higher level of credit needs $d$ or a lower level of credit access $\theta$ implies that firms are more likely to face tighter credit constraints. Consequently, the optimization problem of a firm with productivity $\phi$, credit access $\theta$, and credit needs $d$ is given by: ${ }^{4}$

$$
\begin{gathered}
\max _{p, q, a}\left(p-\frac{\tau q^{\alpha}}{\phi}\right)(q a)^{\sigma-1} \frac{p^{-\sigma}}{P^{1-\sigma}} Y-f_{x} \frac{a^{1+\epsilon}}{1+\epsilon}-f_{d} q^{\beta} \\
\text { s.t. } \theta\left[\left(p-(1-d) \frac{\tau q^{\alpha}}{\phi}\right)(q a)^{\sigma-1} \frac{p^{-\sigma}}{P^{1-\sigma}} Y-(1-d)\left(f_{x} \frac{a^{1+\epsilon}}{1+\epsilon}+f_{d} q^{\beta}\right)\right] \\
\geq d\left[\frac{\tau q^{\alpha}}{\phi}(q a)^{\sigma-1} \frac{p^{-\sigma}}{P^{1-\sigma}} Y+f_{x} \frac{a^{1+\epsilon}}{1+\epsilon}+f_{d} q^{\beta}\right]
\end{gathered}
$$

where budget constraint (3) can be viewed as the "cash flow constraint" condition, in the same spirit as Manova (forthcoming) and Feenstra et al. (2011). Solving this optimization problem by choosing price $p$, quality $q$, and advertisement $a$ yields

$$
\begin{aligned}
p & =\frac{\sigma}{\sigma-1}\left(1+d \frac{(1-\theta) \lambda}{\theta(1+\lambda)}\right) \frac{\tau q^{\alpha}}{\phi} \\
(q a)^{\sigma-1} \frac{p^{1-\sigma}}{P^{1-\sigma}} Y & =\frac{\sigma \beta}{(1-\alpha)(\sigma-1)}\left(1+d \frac{(1-\theta) \lambda}{\theta(1+\lambda)}\right) f_{d} q^{\beta} \\
(q a)^{\sigma-1} \frac{p^{1-\sigma}}{P^{1-\sigma}} Y & =\frac{\sigma}{\sigma-1}\left(1+d \frac{(1-\theta) \lambda}{\theta(1+\lambda)}\right) f_{x} a^{1+\epsilon}
\end{aligned}
$$

where $\lambda$ is the Lagrangian multiplier associated with the budget constraint condition (3) (see Appendix A for the detailed derivation of first-order conditions).

Equation (5), together with (6), yield the relation between optimal quality $q$ and optimal ad-

\footnotetext{
${ }^{3}$ We also consider the case that firms only need to raise outside capital for fixed costs in Proposition 6 and the proof is in Appendix.

${ }^{4}$ For simplicity of notation, we suppress variety $\omega$ and subscripts of country $(i, j)$. It should be also pointed out that we do not consider the intertemporal structure of costs of borrowing from banks as the current model is a static, one-period model.
} 
vertisement $a$ :

$$
\frac{\beta}{1-\alpha} f_{d} q^{\beta}=f_{x} a^{1+\epsilon}
$$

In other words, investment in quality and expenditure on advertising are complements. This expression, together with the budget constraint (3) and conditions (4) and (5), yield:

$$
\frac{\sigma \beta}{(1-\alpha)(\sigma-1)}\left(1+d \frac{(1-\theta) \lambda}{\theta(1+\lambda)}\right) \geq\left(1-d+\frac{d}{\theta}\right)\left(\frac{\beta}{1-\alpha}+\frac{\beta}{(1+\epsilon)(1-\alpha)}+1\right)
$$

Let $\frac{\beta}{(1-\alpha)(\sigma-1)} \equiv \Lambda$ and $\frac{1+\epsilon}{\sigma-1} \equiv 1+\Theta$. Given credit needs $d$, there exists a cutoff level of credit access $\theta_{h}$ such that budget constraint (3) is binding if and only if $\theta<\theta_{h} \cdot{ }^{5}$ Likewise, given credit access $\theta$, there exists a cutoff level of credit needs above which the budget constraint (3) is binding. Next, we analyze two cases according to whether budget constraint (3) is binding.

Case 1: The budget constraint (3) is binding, i.e., $\theta<\theta_{h}$.

Here, equation (8) yields:

$$
\left(1+d \frac{(1-\theta) \lambda}{\theta(1+\lambda)}\right)=\left(1-d+\frac{d}{\theta}\right)\left(\frac{\sigma+\sigma \Theta-\Theta}{\sigma+\sigma \Theta}+\frac{1}{\sigma \Lambda}\right)
$$

Let $\left(1+d \frac{(1-\theta) \lambda}{\theta(1+\lambda)}\right) \equiv \Delta$, which reflects the price distortion based on equation (4). We call this effect the price distortion effect. It should be noted that the price distortion effect is independent of the assumption of endogenous quality (see Appendix B for the proof of the case when quality is exogenous). It is obvious that the extent to which price is distorted is related to credit access $\theta$ and credit needs $d$. Lower credit access $\theta$ or higher credit needs $d$ increases the price distortion caused by the binding budget constraint. The intuition behind the price distortion effect is as follows. Given product quality, a firm facing tighter credit constraints will reduce its output, leading to excess demand for its product at the initial price level, which in turn pushes up its price.

Now, equation (3), together with (4) and (7), imply that the optimal quality chosen by firms satisfies the following condition:

$$
q^{\frac{\Theta \beta}{1+\Theta}-(1-\alpha)(\sigma-1)}=\frac{\Delta^{-\sigma}}{\sigma \Lambda f_{d}}\left(\frac{\Lambda(\sigma-1) f_{d}}{f_{x}}\right)^{\frac{1}{1+\Theta}}\left(\frac{\sigma}{\sigma-1} \frac{\tau}{\phi}\right)^{1-\sigma} \frac{Y}{P^{1-\sigma}}
$$

Define Condition (i) as $\Theta \beta>(1-\alpha)(\sigma-1)(1+\Theta)$. Under condition (i), there is a positive correlation between firm productivity $\phi$ and quality $q$, given credit access $\theta$ and credit needs $d$. This suggests that more productive firms choose higher quality, which is consistent with the findings of the quality-and-trade literature. Given firm productivity, Condition (i) also ensures that a firm

\footnotetext{
${ }^{5}$ Equation (8) implies that budget constraint (3) is binding if and only if $\theta<\theta_{h}$, where $\theta_{h}=$ $\frac{d(\Lambda(\sigma+\sigma \Theta-\Theta)+1+\Theta)}{\sigma \Lambda(1+\Theta)-(1-d)(\Lambda(\sigma+\sigma \Theta-\Theta)+1+\Theta)}$.
} 
with more credit access or less credit needs chooses higher optimal quality. This is because equation (9) tells us that, given productivity, an increase in $\theta$ or a reduction in $d$ (i.e., more credit access or lower credit needs) relaxes the firm's credit constraints through the change in $\Delta$, and therefore induces the firm to choose a higher optimal quality $q$, which in turn leads to a higher price set by the firm. We call this mechanism the quality adjustment effect.

Hence, the optimal pricing rule (4), together with (9), yield:

$$
p=\Delta^{1-\sigma \Psi}\left(\frac{1}{\sigma \Lambda f_{d}}\right)^{\Psi}\left(\frac{\Lambda(\sigma-1) f_{d}}{f_{x}}\right)^{\frac{\Psi}{1+\Theta}}\left(\frac{\sigma}{\sigma-1} \frac{\tau}{\phi}\right)^{1+(1-\sigma) \Psi}\left(\frac{Y}{P^{1-\sigma}}\right)^{\Psi}
$$

where $\Psi=\frac{\alpha(1+\Theta)}{\Theta \beta-(1-\alpha)(\sigma-1)(1+\Theta)}>0$. Define Condition (ii) as $(\sigma-1)(1+\Theta)>\Theta \beta$. If Condition (ii) holds (in addition to Condition (i) ), then a firm's optimal price is positively correlated with firm productivity. Define Condition (A) as $\frac{1}{\beta}>\frac{1}{\sigma-1}-\frac{1}{1+\epsilon}>\frac{1-\alpha}{\beta}$. Condition (i) and (ii) combined is equivalent to the condition (A). If condition (A) holds, a firm with higher productivity charges higher optimal prices. The intuition behind this positive correlation between firm productivity and export prices is due to two opposing forces: the quality adjustment effect (i.e., higher-productivity firms set higher prices via selling higher-quality products) and the productivity effect (i.e., higher-productivity firms are able to charge lower prices via having lower marginal cost for any given quality). When the quality adjustment effect dominates the productivity effect under the endogenous-quality model, there exists a positive relationship between firm productivity and export prices.

Under condition (A), $1-\sigma \Psi<0$ is also satisfied. Hence, tighter credit constraints (via either higher credit needs $d$ or lower credit access $\theta$ ) eventually reduce the optimal price. This implies that the quality adjustment effect dominates the price distortion effect. Here, the impact of credit constraint on export prices also depends on two opposing forces: One is caused by the price distortion $\Delta$ induced by credit constraints (i.e., the price distortion effect). The other is caused by the optimal product quality chosen by the firm (i.e., the quality adjustment effect). The former effect tends to increase the optimal price when a firm faces higher credit needs $d$ and lower credit access $\theta$ (i.e., when $d$ increases or $\theta$ decreases, the price distortion $\Delta$ increases and therefore price increases according to equation (4)). However, the latter effect tends to reduce the optimal price when a firm faces tighter credit constraints. This is because tighter credit constraints induce $\Delta$ to increase, and hence induce firms to produce a lower-quality product according to equation (9), which in turn lowers optimal price according to equation (4). Under condition (A), the quality adjustment effect dominates, and therefore, firms facing tighter credit constraints set lower prices. The graph in the left panel of Figure 1 illustrates the relationship between prices, productivity, and credit constraints when condition (A) holds under Case 1: the solid line corresponds to more relaxed credit constraint (i.e., a higher $\theta$ and a lower $d$ ), and the dashed line captures the tighter credit constraint situation (i.e., a lower $\theta$ and a higher $d$ ). 
Figure 1: The relationship between prices, TFP, and credit constraints

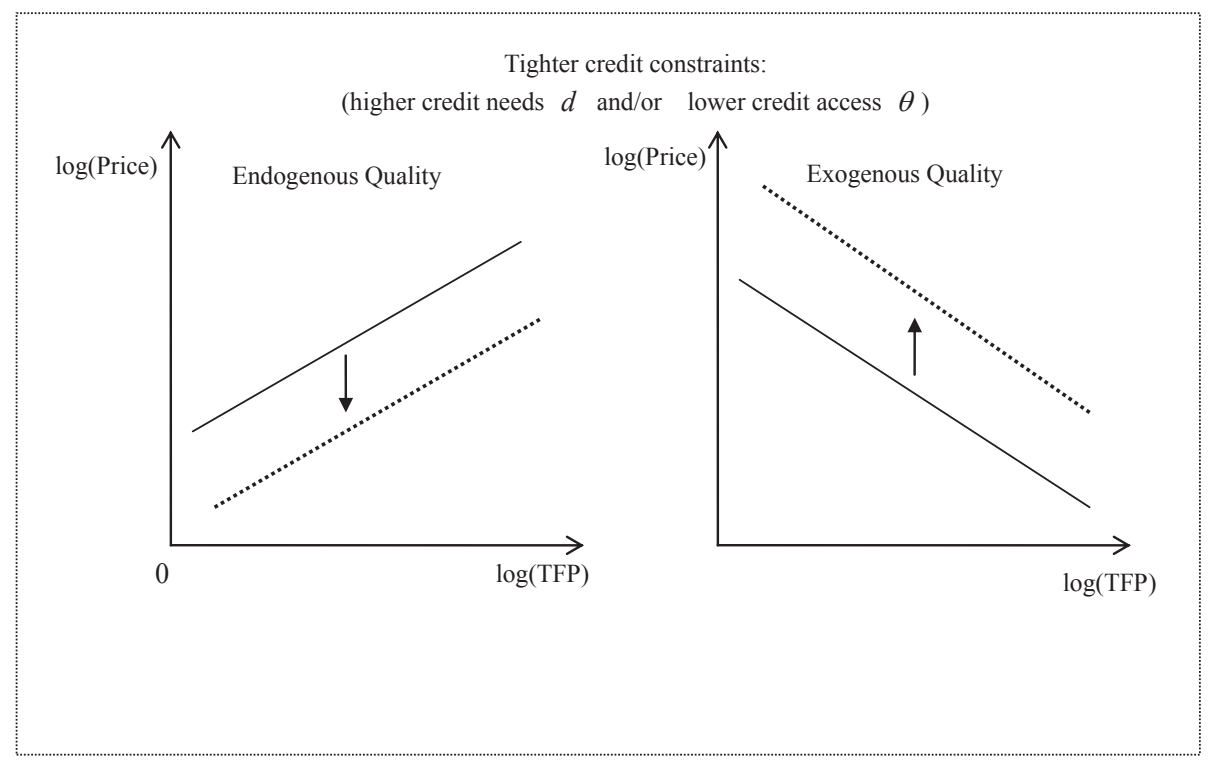

Case 2: The budget constraint (3) is nonbinding, i.e., $\theta>\theta_{h}$.

Equation (5), together with (4) and (7), imply:

$$
q^{\frac{\Theta \beta}{1+\Theta}-(1-\alpha)(\sigma-1)}=\frac{1}{\sigma \Lambda f_{d}}\left(\frac{(\sigma-1) \Lambda f_{d}}{f_{x}}\right)^{\frac{1}{1+\Theta}}\left(\frac{\sigma}{\sigma-1} \frac{\tau}{\phi}\right)^{1-\sigma} \frac{Y}{P^{1-\sigma}}
$$

Under Condition (i), the firm with higher productivity will choose higher quality. Thus, equation (11), together with (4), imply that the optimal pricing rule is given by

$$
p=\left(\sigma \Lambda f_{d}\right)^{-\Psi}\left(\frac{(\sigma-1) \Lambda f_{d}}{f_{x}}\right)^{\Psi /(1+\Theta)}\left(\frac{\sigma}{\sigma-1} \frac{\tau}{\phi}\right)^{1+(1-\sigma) \Psi}\left(\frac{Y}{P^{1-\sigma}}\right)^{\Psi}
$$

If Condition (A) holds, then $1+(1-\sigma) \Psi<0$, and so (11) implies that there is a positive relationship between price and productivity. Therefore, the solid line in the left panel of Figure 1 still describes the relationship between price and $\log (\mathrm{TFP}) .{ }^{6}$ However, the optimal prices are not affected by credit access $\theta$ or credit needs $d$ anymore, as firms have sufficient credit access compared to their credit needs (i.e., $\theta>\theta_{h}$ ). Therefore, the solid line in the left panel of Figure 1 does not shift as $\theta$ or $d$ changes.

In the rest of this paper, we shall concentrate on the central case when Case 1 and Condition (A) both hold. ${ }^{7}$ From the above analysis, given Case 1 and Condition (A), we have the following

\footnotetext{
${ }^{6}$ In this paper, log refers to natural logarithm.

${ }^{7}$ As Johnson (2012) noted, in terms of sheer numbers, sectors in which export prices rise with the threshold for exporting dominate the data. This implies that the pattern in most sectors is consistent with models of quality hetero-
} 
four testable propositions based on the endogenous-quality model:

Proposition 1 When firms can choose endogenous product quality, the more productive firms choose higher product quality and set higher prices.

Proposition 2 Given the credit needs $d$ and firm productivity, lower level of credit access (i.e., a lower $\theta$ ) reduces the optimal price set by a firm.

Proposition 3 Given the credit access $\theta$ and firm productivity, tighter credit constraints resulting from higher credit needs (i.e., a higher d) reduce the optimal price set by a firm.

Proposition 4 (Quality Adjustment Effect): Given productivity, tighter credit constraints (higher d or lower $\theta$ ) lower the optimal product quality chosen by a firm.

The above propositions ( 1 through 4 ) are based on the assumption that quality is endogenously chosen by firms and therefore there could be heterogeneity of product quality across firms.

\section{Exogenous Quality}

The following proposition (5) is based on the analysis of the exogenous-quality model. For this purpose, we carry out analyses based on the original Melitz-type model (Melitz, 2003), in which quality is exogenously fixed across firms. In this case, quality adjustment effect does not exist and productivity only affects marginal cost, leading to the optimal price decreasing in productivity. The intuition for this case is straightforward: more productive firms face lower marginal cost of production and hence charge lower prices to outperform the market. Obviously, the quality adjustment effect does not exist. Hence, tighter credit constraints (i.e., a higher $d$ or a lower $\theta$ ) increase the optimal prices charged by firms in the exogenous-quality Melitz-type model. See the graph in the right panel of Figure 1 for illustration. We summarize the properties for the exogenous-quality model in the following proposition (see Appendix B for the proof of Proposition 5).

Proposition 5 When quality is exogenous, a more productive firm sets a lower price. Moreover, tighter credit constraints (higher $d$ or lower $\theta$ ) increase the optimal price set by a firm.

\section{Only Fixed Costs are Externally Financed}

In the earlier discussion, we assume that all firms are subject to credit constraints in paying all costs. Therefore, both the variable costs and fixed costs cannot be totally financed internally and firms need to raise outside capital for a fraction $d \in(0,1)$ of the variable costs and the fixed 
costs including the fixed marketing cost and the fixed quality investment cost. However, if the firms only need to raise outside capital for a fraction $d \in(0,1)$ of fixed costs (but not the variable costs), price distortion induced by credit constraints does not exist. As a result, the optimal price is unrelated to credit constraint when quality is exogenous. We summarize this case in the following proposition (see Appendix C for the proof of Proposition 6).

Proposition 6 When only fixed costs are financed by outside capital and variable costs can be totally financed internally, tighter credit constraints (i.e., a higher $d$ or a lower $\theta$ ) reduce the optimal price if quality is endogenous. In this case, prices increase with productivity, ceteris paribus. However, when quality is exogenous, the optimal price is unrelated to credit constraints. In this case, prices decrease with productivity, ceteris paribus.

The discussion in this section suggests that there are two competing theories to explain the relationship between firm productivity and export prices as well as the effect of credit constraints on the optimal price. As illustrated in Figure 1, the model that assumes that quality is endogenous yields a positive relationship between productivity and export prices, and we should expect tighter credit constraints to lower the optimal prices set by the firm as the quality adjustment effect dominates. On the other hand, the model that assumes that quality is exogenous yields a negative relationship between productivity and export prices, and we should expect that tighter credit constraints increase the optimal prices as the only effect that exists is the price distortion effect. In the next section we use data from China to test the relationship between productivity and prices and the impact of credit constraints on export prices as well as the quality adjustment mechanism. It will be seen that our results support the endogenous-quality model.

\section{Empirical Specification, Data and Measurement}

\subsection{Empirical Specification}

The propositions in Section 2 imply that export prices are affected by credit access or credit needs. We test the proposed propositions with the following baseline reduced-form equation:

$$
\log \text { price }_{f p c t}=b_{0}+b_{1} \log \left(\text { TFP }_{f t}\right)+\gamma X_{f t}+\chi_{1} \text { FinDev }_{r}+\chi_{2} \text { ExtFin }_{i}+\mu \Gamma_{f t}+\varphi_{p c}+\varphi_{t}+\epsilon_{f p c t}
$$

where price $_{\text {fpct }}$ represents the unit value export price of product $p$ (disaggregated at HS 8-digit level, which is the most disaggregate level for Chinese products) exported by firm $f$ located in province $r$ to destination country $c$ in year $t$; $T F P_{f t}$ denotes a firm $f^{\prime}$ 's productivity in year $t$; $X_{f t}$ is a vector of time-varying firm attributes of firm $f$ in year $t$; FinDev $v_{r}$ captures the credit access in province $r$ where the firm is located; $\operatorname{ExtFin}_{i}$ reflects the credit needs at industry $i$ and external finance dependence is one of the most important credit needs measures; $\Gamma_{f t}$ is a 
vector of input quality by firm $f$ at year $t ; \varphi_{p c}$ and $\varphi_{t}$ are fixed effect terms of product-destination and year, respectively; $\epsilon_{f p c t}$ is the error term that includes all unobserved factors that may affect the export prices. The vector of time-varying firm attributes $X_{f t}$ includes firm size and capital intensity: employment is used to stand for firm size and to control for the economies of scale; capital-labor ratio, $\mathrm{K} / \mathrm{L}$, is used to control for production technique, which may not be captured by the technology level of a firm. The input quality $\Gamma_{f t}$ is measured by average payments for each worker to capture the quality of labor input, and the share of college workers in total employment in alternative exercises.

As there are different sources of variation of export prices (e.g., firm, product, destination country), we deal with the sources of price variation carefully to identify the effects of credit constraints on export prices. Except for the year fixed effects, in the baseline regression, we exploit the variation across firms within a product-destination market by including the product-destination fixed effect terms, $\varphi_{p c}$, and cluster error terms at product-destination level. We also employ year fixed effects and product fixed effects, $\varphi_{p}$, and cluster error terms at product level in an alternative specification where the dependent variable is (log) average export price by firm and HS- 8 product $\left(\log\right.$ price $\left._{f p t}\right)$. We report results based on both specifications as baseline regressions and both results support the predictions of the endogenous-quality model.

It is worth noting that there exist different mappings between industry $i$ and product $p$, when we use the US data and Chinese data to compute credit needs measures. Therefore, the product or product-destination fixed effect terms refer to different aggregation levels of product in different specifications. When we use Chinese data to compute credit needs measure at industry level based on Chinese industrial classification, we can include HS8-product-destination fixed effects in our baseline regressions and cluster errors at the HS8-product-destination level. However, if we follow the standard literature in trade and finance (e.g., Manova, forthcoming; Kroszner et al., 2007) to measure credit needs based on US data, our product fixed effect terms will be measured at HS4 level, or roughly speaking, at broader industry level, due to the mapping between HS product and ISIC (International Standard Industrial Classification) industry. See more detailed discussion on this issue in Section 3.3.2. about measures of credit needs.

\subsection{Firm-level and Product-level Data}

To investigate the relationship between firms' productivity and their export prices as well as the role of credit constraints, we merge the following two highly disaggregated large panel Chinese data sets: (1) the firm-level production data, and (2) the product-level trade data. The sample period is between 2000 and 2006.

The data source for the firm-level production data is the annual surveys of Chinese manufacturing firms, which was conducted by the National Bureau of Statistics of China (NBSC). The database covers all state-owned enterprises (SOEs), and non-state-owned enterprises with annual 
sales of at least 5 million RMB (Chinese currency). ${ }^{8}$ Between 2000 and 2006, the approximate number of firms covered by the NBSC database varied from 163,000 to 302,000. This database has been widely used by previous studies of Chinese economy and other economic issues using Chinese data (e.g., Cai and Liu, 2009; Lu et al., 2010; Feenstra et al., 2011; Brandt et al., 2012; among others) as it contains detailed firm-level information of manufacturing enterprises in China, such as ownership structure, employment, capital stock, gross output, value added, firm identification (e.g., company name, telephone number, zip code, contact person, etc.), and complete information on the three major accounting statements (i.e., balance sheets, profit \& loss accounts, and cash flow statements). Of all the information contained in the NBSC Database, we are mostly interested in the variables related to measuring firm total factor productivity and credit constraints. In order to merge the NBSC Database with the product-level trade data so as to obtain the export prices for each firm, we also use firm identification information.

As there are some reporting errors in the NBSC database, to clean the NBSC sample, we follow Feenstra et al. (2011), Cai and Liu (2009), and the General Accepted Accounting Principles to discard observations for which one of the following criteria is violated: (1) the key financial variables (such as total assets, net value of fixed assets, sales, gross value of industrial output) cannot be missing; (2) the number of employees hired by a firm must not be less than 10; (3) the total assets must be higher than the liquid assets; (4) the total assets must be larger than the total fixed assets; (5) the total assets must be larger than the net value of the fixed assets; (6) a firm's identification number cannot be missing and must be unique; and (7) the established time must be valid (e.g., the opening month cannot be later than December or earlier than January).

The second database we use is the Chinese trade data at HS 8-digit level, provided by China's General Administration of Customs. This Chinese Customs Database covers the universe of all Chinese exporters and importers in 2000-2006. It records detailed information of each trade transactions, including import and export values, quantities, quantity units, products, source and destination countries, contact information of the firm (e.g., company name, telephone, zip code, contact person), type of enterprises (e.g. state owned, domestic private firms, foreign invested, and joint ventures), and customs regime (e.g. "Processing and Assembling" and "Processing with Imported Materials"). Of all the information in the customs database, export values and quantities are of special interest to this study as they yield unit value export prices.

In order to merge the above two databases, we match the product-level trade data contained in the Chinese Customs Database to data on manufacturing firms contained in the NBSC Database, based on the contact information of firms, because there is no consistent coding system of firm identity between these two databases. ${ }^{9}$ Our matching procedure is done in three steps. First,

\footnotetext{
${ }^{8}$ It equals US\$640,000 approximately, according to the official end-of-period exchange rate in 2006, reported by the central bank of China.

${ }^{9}$ In the NBSC Database, firms are identified by their corporate representative codes and contact information. While in the Customs Database, firms are identified by their corporate custom codes and contact information. These two
} 
the vast majority of firms (89.3\%) are matched by company names exactly. Second, an additional $10.1 \%$ are matched by telephone number and zip code exactly. Finally, the remaining $0.6 \%$ of firms are matched by telephone number and contact person name exactly. ${ }^{10}$ Compared with the manufacturing exporting firms in the NBSC Database, the matching rate of our sample (in terms of the number of firms) varies from $52 \%$ to $63 \%$ between 2000 and 2006 , which covers $56 \%$ to $63 \%$ of total export value reported by the NBSC Database between 2000 and 2006. In total, the matched sample covers more than $60 \%$ of total value of firm exports in the manufacturing sector reported by the NBSC Database and more than $40 \%$ of total value of firm exports reported by the Customs Database.

\subsection{Measurement}

\subsubsection{Measures of Credit Access}

In order to measure credit access, we collect data on the balances of total bank credits, long-term bank loans, and short-term bank loans and calculate the bank loans to GDP ratio at the provincial level. As regional heterogeneity in available bank credits and loans to firms is huge in China, we believe that bank loans by province serve as a good proxy for credit access, which reflects regional financial development. Our sample includes 31 provincial-level regions (including 22 provinces, 4 municipalities, and 5 autonomous regions). The data source is Almanac of China's Finance and Banking (2000-2007). If the level of financial development is higher, then there is more credit access for firms and so we expect to see increases in optimal prices under the endogenous-quality model.

Another measure we use to proxy for credit access is firm ownership. We compare state-owned enterprises (SOE) with domestic private enterprises (DPE) and multinational corporation (MNC) with joint venture (JV). We compare different types of firms in China because the literature clearly suggests that given the underdevelopment of Chinese financial markets, the Chinese DPE face less credit access than SOE do, because SOE can finance a larger share of their investments through external financing from bank loans provided by state-owned banks. For example, Boyreau-Debray and Wei (2005) point out that the Chinese banks-mostly state owned-tend to offer easier credit to SOE. Dollar and Wei (2007) and Riedel et al. (2007) report that private firms rely significantly less on bank loans and significantly more on retained earnings as well as family and friends to finance investments. Song et al. (2011) also show that SOE finance more than 30 percent of their investments through bank loans compared to less than 10 percent for domestic private firms, and other forms of official market financing (through bank loans) are marginal for private firms in China as private firms rely more on internal or informal financing. Therefore, it is safe to conclude

coding systems are neither consistent, nor transferable with each other.

${ }^{10}$ In order to obtain more precise matching, we do not use contact person and zip code to match trade transactions to manufacturing firms since there are many different companies, which have the same contact person name in the same zip-code region. 
that SOE in China face more credit access, compared to DPE. At the same time, the literature also indicates that multinational companies have better credit access than joint ventures as multinational companies are able to reallocate resources on a global scale and finance their subsidiaries from headquarters or other affiliates. Therefore, according to the theory presented above, if the endogenous-quality model correctly captures the firm's pricing behavior under credit constraints, we expect the optimal prices set by SOE to be higher than those by DPE and the optimal prices set by MNC higher than those by JV, respectively.

\subsubsection{Measures of Credit Needs}

Following Manova et al. (2011), we employ four different measures of an industry's financial vulnerability to proxy for credit needs at the industry level. The idea is that if an industry is more financially vulnerable, it is more likely to face binding credit constraint. These measures have been widely used in the literature on the role of credit constraints in international trade and growth. It should be noted that these measures are meant to reflect technologically determined characteristics of each industry that are beyond the control of individual firms. Therefore, these measures of industrial financial vulnerability are inherent to the nature of the industry, which should be viewed as exogenously given for each individual firm.

These four measures are external finance dependence, R\&D intensity, inventory-to-sales ratio, and asset tangibility. An industry's external finance dependence (ExtFin $\left.)_{i}\right)$ is defined as the share of capital expenditure not financed with cash flows from operations. If external finance dependence is high, the industry is more financially vulnerable and have higher credit needs. $\mathrm{R} \& \mathrm{D}$ intensity is defined as $\mathrm{R} \& \mathrm{D}$ spending to total sales ratio $\left(R D_{i}\right)$, which can also reflect the industry's financial vulnerability, because research and development activities are capital-intensive. Typically, R\&D expenditures, as the impetus for production, occur before products can be manufactured and successfully marketed and thus require large financial resource input. Third, we use inventory-to-sales ratio ( Invent $_{i}$ ) as it captures the duration of the manufacturing process and the working capital that a firm requires in order to maintain inventory so as to meet demand. Last but not least, a measure of asset tangibility $\left(\operatorname{Tang}_{i}\right)$ can also capture the liquidity situation of an industry and it is defined as the share of net value of fixed assets (such as plants, properties and equipments) in total book value assets. Among these four measures, higher external finance dependence, R\&D intensity, and inventory-to-sales ratio imply tighter credit constraint (i.e., a higher $d$ ), while higher asset tangibility implies less stringent credit constraints (i.e., a lower $d$ or, equivalently, a higher $\theta$ ) as tangible assets can serve as collateral for borrowing and help to alleviate credit constraints. It may be debatable whether asset tangibility belongs to credit needs measure or credit access measure. Nonetheless, regardless of whether we view tangibility as indicator of credit needs or credit access, it does not change the fact that higher tangibility implies less stringent credit constraint and, therefore, according to the theory, induces higher export prices set by 
the firm. So we expect that the coefficients on $\operatorname{ExtFin}_{i}, R D_{i}$, and Invent $_{i}$ are negative, while the coefficient on Tang $_{i}$ is positive.

In the main tests, we employ these four measures of industrial financial vulnerability constructed by Kroszner et al. (2007), based on data on all publicly traded U.S.-based companies from Compustat's annual industrial files. These measures have also been used by Manova et al. (2011). They are constructed following the methodology of Rajan and Zingales (1998) and Claessens and Laeven (2003). They are averaged over the 1980-1999 period for the median U.S. firm in each sector, and appear to be very stable over time. The four indicators of industries' financial vulnerability are available for 29 sectors in the ISIC 3-digit classification system. As our dependent variable is export price of products, we match the HS 6-digit product codes to those ISIC 3-digit sector categories by employing Haveman's concordance tables. ${ }^{11}$ This matching method has been adopted by Manova et al. (2011). The rationale behind this matching is that we can categorize firms into different industries according to what products they produce and, hence, sell to foreign markets. Therefore, when we use credit needs measures based on US data in the baseline regression, we include product or product-destination fixed effects at HS4 level rather than HS6 or HS8 level, because HS6-product fixed effects will absorb the effect of credit needs. We acknowledge that this matching based on US data cannot be perfect. Hence, in order to avoid any potential bias from the matching, we also use Chinese firm-level data to directly construct the Chinese-data-based measure of credit needs at industry level to complement our analysis using the US-data-based measures.

The application of these measures calculated based on US data to countries other than the US is quite common in the literature (e.g., Rajan and Zingales, 1998; Kroszner et al., 2007; Manova et al., 2011). The rationale is that these measures in an industry of financial needs are determined by the nature of the industry, which is supposed to be the same across countries. As argued by Rajan and Zingales (1998), Kroszner et al. (2007), and Claessens and Laeven (2003), among others, there is a technological reason why some industries depend more on external finance than others and these technological differences persist across countries. Manova et al. (2011) also argue that the ranking of industries in terms of their financial vulnerability remains relatively stable across countries. In fact, Rajan and Zingales (1998) explicitly indicate that "most of the determinants of ratio of cash flow to capital are likely to be similar worldwide: the level of demand for a certain product, its stage in the life cycle, and its cash harvest period". This implies that, in principle, the measures calculated based on data from any country with well-functioning capital markets should be applicable to our study. Therefore, we use an industry's financial vulnerability calculated based on US data as measures of its credit needs in our baseline regressions.

However, to account for any potential bias from the matching, we also construct the major

\footnotetext{
${ }^{11}$ The concordance table can be accessed via http:/ / www.macalester.edu/research/economics/page/haveman/Trade. Resources/tradeconcordances.html.
} 
indicator of credit needs, ExtFin, calculated at the 2-digit Chinese Industrial Classification (CIC) level using Chinese firm-level data. Our results are reported in Table 1 (in ascending order of credit needs), which can be easily compared with the measures calculated based on US data. ${ }^{12}$ Due to the immaturity of Chinese financial markets, capital expenditures by Chinese firms are more likely to be financed internally. As a result, the mean external finance dependence in China is lower than that of the US. ${ }^{13}$ Nonetheless, we find that the rankings of industries in external finance dependence in China and in the US are similar to each other, with reasonable difference across industries as the two countries use different industrial classification system. This is consistent with the finding in prior studies that the external finance dependence of U.S. firms is a good proxy for other countries. For example, the tobacco industry is always at the top of the ranking list and is less credit-constrained, while the petroleum products industry and professional and scientific equipment industry are at the bottom of the ranking list as they are usually more technology-intensive and need more external capital. It is worth noting that the CIC industry code is a different classification system compared with HS or ISIC. Each firm belongs to one CIC, but it can produce and export multiple HS8 products. To sort out the price variation due to product-level characteristics and the potential correlation of error terms within each product, when we use ExtFin based on Chinese data, we include HS8-product or HS8-product-destination fixed effects and also cluster errors at the corresponding levels.

\subsubsection{Measures of Productivity}

To capture firms' productivity as a control variable in our regression analysis, we estimate both total factor productivity (TFP) and labor productivity (measured by value added per worker).

For TFP we first use a Cobb-Douglas production function as estimation specification: ${ }^{14}$

$$
Y_{f t}=A_{f t} L_{f t}^{\beta_{l}} K_{f t}^{\beta_{k}}
$$

where production output of firm $f$ at year $t, Y_{f t}$, is a function of labor, $L_{f t}$, and capital, $K_{f t} ; A_{f t}$ captures firm $f^{\prime}$ 's TFP in year $t$. We use deflated firm's value-added to measure production output. We do not include intermediate inputs (materials) as one of the input factors in our main results because the prices of imported intermediate inputs are different from those of domestic intermediate inputs. As processing trade in China accounts for a substantial proportion of its total trade since 1995, using China's domestic deflator to measure its imported intermediate input would

\footnotetext{
${ }^{12}$ Data available in year 2004-2006 in the NBSC Database. We calculate the aggregate rather than the median external finance dependence at 2-digit industry level, because the median firm in Chinese database often has no capital expenditure. In our sample, approximately $68.1 \%$ firms have zero capital expenditure. Hence, we cannot use median firm approach to calculate external finance dependence.

${ }^{13}$ According to our calculation, the mean external finance dependence in China is approximately -0.57 while the mean external finance dependence from the US data is about -0.16 .

${ }^{14}$ An alternative specification would be to use a trans-log production function, which also leads to similar estimation results.
} 
raise another unnecessary estimation bias (Feenstra et al., 2011). However, for robustness check, we also estimate TFP by treating material as an intermediate input. It turns out that including intermediate inputs (materials) in the estimation of TFP does not alter the results of our empirical test of the theory.

As the traditional OLS estimation method suffers from simultaneity bias and selection bias, we employ the augmented Olley-Pakes (1996) approach to deal with both the simultaneity bias and selection bias in the measured TFP in the main part of our empirical test. Our approach is based on the recent development in the application of the Olley-Pakes method, for example, Amiti and Konings (2007), Feenstra et al. (2011), and Yu (2011). However, to check for robustness, we also employ other approaches to estimate TFP (e.g., Levinsohn and Petrin, 2003; Ackerberg et al., 2006; De Loecker and Warzynski, 2012). We find that all variants of TFP estimate support the predictions of the endogenous-quality model that tighter credit constraints lower export prices. We briefly describe the augmented Olley-Pakes method used in our TFP estimation as follows.

First, to measure a firm's inputs (labor and capital) and output in real term, we use different input price deflators and output price deflators, drawing the data directly from Brandt et al. (2012). ${ }^{15}$ In Brandt et al. (2012), the output deflators are constructed using "reference price" information from China's Statistical Yearbooks and the input deflators are constructed based on output deflators and China's national input-output table (2002).

Second, we construct the real investment variable by adopting the perpetual inventory method to model the law of motion for real capital and real investment. To capture the depreciation rate, we use each firm's real depreciation rate provided by the Chinese firm-level data.

Furthermore, to take into account firm's trade status in the TFP realization, following Amiti and Konings (2007) we include two trade-status dummy variables-an export dummy (equal to one for exports and zero otherwise) and an import dummy (equal to one for imports and zero otherwise). In addition, as we are dealing with Chinese data and our sample period is between 2000 and 2006, we include a WTO dummy (i.e., one for a year after 2001 and zero for before) in the Olley-Pakes estimation, as have been done by Feenstra et al. (2011) and Yu (2011). The WTO dummy can capture the effect of China joining WTO on the realization of the TFP because the WTO accession in 2001 was a positive demand shock for China's exports. Our estimates of TFP coefficients at the 2-digit industry level are reported in Table 2 and the magnitudes of our estimates are similar to those reported by Feenstra et al. (2011).

\section{Results}

In this section, we report our empirical results, computed as the cluster-robust standard error estimator and clustering at the corresponding product-destination or product level. Our results

\footnotetext{
${ }^{15}$ The data can be accessed via http://www.econ.kuleuven.be/public/N07057/CHINA/appendix/.
} 
favor the theoretical predictions based on the endogenous-quality model. Interestingly, we also find evidence for the exogenous-quality model using quality-adjusted price and therefore confirm the mechanism of quality adjustment.

\subsection{Baseline Results: Effects of Credit Constraints on Export Prices}

We are interested in examining the impacts of credit access and credit needs on export prices. According to Propositions 2 and 3, if the endogenous-quality model is correct, we should expect that lower credit access or higher credit needs lowers the optimal price set by the firm. Otherwise, if the exogenous-quality model is correct, we should expect the opposite effects of credit access and credit needs on export prices.

We report our baseline results based on four credit needs measures computed by US data in two tables (Table 3 and Table 4). Our results indicate that the predictions of the endogenousquality model are more consistent with reality than the exogenous-quality model. In each of the four sets of results, we use three types of bank loans to GDP ratio and the different types of firm ownership to control for credit access, and employ one of the four measures of financial vulnerability (i.e., external finance dependence, R\&D intensity, inventory-to-sales ratio, and asset tangibility) to proxy for credit needs. Table 3 presents the results using external finance dependence in specifications (1)-(5) and R\&D intensity in specifications (6)-(10). On the other hand, Table 4 reports the results based inventory-to-sales ratio in specifications (1)-(5) and asset tangibility in specifications (6)-(10).

In Tables 3 and 4, specifications (1)-(3) and (6)-(8) show the regression results under three different measures of credit access using bank loans. Specifications (4)-(5) and (9)-(10) include two firm-type dummy variables: SOE, which is equal to 1 if the firm belongs to state-owned enterprises (SOE) and 0 if it belongs to domestic private enterprises (DPE); and MNC, which is equal to 1 if the firm is a multinational corporation (MNC) and 0 if it belongs to a joint venture (JV). According to Proposition 2 and further discussion in Section 3.3.1., we expect the coefficients on three types of bank loans as well as SOE and MNC to be positive, if the endogenous-quality model is correct. We find that the coefficients on all measures of credit access are positive and significant at $1 \%$ level, implying that firms with more access to bank loans set higher prices, and the prices set by SOE and MNC are higher than the prices set by DPE and JV, respectively. These results support Proposition 2.

Likewise, if the endogenous-quality model is correct, according to Proposition 3 and the further discussion in Section 3.3.2., we should expect the coefficients on external finance dependence, $R \& D$ intensity, and inventory-to-sales ratio to be negative while the coefficients on asset tangibility to be positive, because firms in industries with higher external finance dependence, $R \& D$ ratio, and inventory-to-sales ratio face tighter credit constraints whereas those with more tangible assets have more relaxed credit constraints. Again, the results presented in Tables 3-4 confirm the 
endogenous-quality model: given the level of credit access, higher credit needs lowers the optimal prices with statistical significance at $1 \%$ level. ${ }^{16}$

Next, we employ the price variation across firms within the same product (i.e., log price by firm $f$ for product $p$ at year $t$ ) as dependent variable and report the results in Tables 5-6. The results are consistent with our previous discussion in Tables 3-4 and support Propositions 2-3, which arise from the endogenous-quality model.

As all the above results use the credit needs measures based on US data, to further verify our baseline results, we also compute the key measurement of credit needs-external finance dependence- - using Chinese firm data, and report regression results in Table 7. Specifications (1)-(5) of Table 7 use (log) average export price by firm and HS8-product-destination as dependent variable, while specifications (6)-(10) use (log) average export price by firm and HS8-product as dependent variable. As discussed in Section 3.3.2., the ranking of industries in external finance dependence calculated based on Chinese data is quite similar to the one based on US data. Thus, as expected, the results based on the external finance dependence from Chinese data are also consistent with the predictions of the endogenous-quality model: the coefficients on credit access are significantly positive; while the coefficients on credit needs are significantly negative. The results are stated in Table 7. To demonstrate robustness, in all subsequent analyses, we run two sets of regressions using external finance dependence computed by US data and Chinese data, respectively. ${ }^{17}$

Moreover, from the theory presented above, if the exogenous-quality model prevails, we should expect to see a negative relationship between firm productivity and export prices. On the contrary, if the endogenous-quality model is more consistent with the reality, we should expect that prices increase in productivity, as stated in Proposition 1. The reason is that firm productivity affects product prices through two channels. On the one hand, higher-productivity firms have lower marginal costs, leading to lower product prices. On the other hand, more productive firms choose to produce goods of higher quality, leading to higher product prices. As the quality effect dominates, the total effect is that prices increase in productivity. In Tables 3-7, when we run regressions of $\log$ (price) on $\log (\mathrm{TFP})$ according to the estimating equation (13), we find that the coefficients on TFP in all specifications are always positive and significant at $1 \%$ level. This indicates that there exists a positive relationship between productivity and prices, which also supports the endogenous-quality model.

\footnotetext{
${ }^{16}$ According to the corporate finance literature, external finance dependence varies by nature for young firms and mature firms. Therefore, in an alternative specification, we include firm age as control variable in the baseline regressions and our baseline results are robust after controlling for firm age.

${ }^{17}$ We report the results using the US-based measure of external finance dependence in the main tables, but the results using the Chinese-based measure are also available upon request.
} 


\subsection{Quality and Quality-Adjusted Prices}

If the mechanism of quality adjustment in our endogenous-quality model is correct, according to equation (9) and Proposition 4, we expect that given productivity, a firm with more credit access or less credit needs chooses higher product quality if product quality is an endogenous choice for the firm. Conversely, if the quality choice is not endogenous, according to Proposition 5, we expect that a more productive firm sets a lower price; moreover, tighter credit constraints increase the optimal price. We now use estimated quality and quality-adjusted price to test the above propositions.

First, we infer quality from observed prices and demand by adopting Khandelwal et al.'s (2011) method. We estimate export "quality" of product $p$ shipped to destination country $c$ by firm $f$ in year $t, q_{f p c t}$, via the following empirical demand equation based on equation (1), the demand equation, in our model:

$$
x_{f p c t}=q_{f p c t}^{\sigma-1} a_{f p c t}^{\sigma-1} p_{f p c t}^{-\sigma} P_{c t}^{\sigma-1} Y_{c t}
$$

where $x_{f p c t}$ denotes the demand for a particular firm's export of product $p$ in destination country $c$. We then take logs of the above equation, and use the residual from the following OLS regression to infer quality:

$$
\log x_{f p c t}+\sigma \log p_{f p c t}=\varphi_{p}+\varphi_{c t}+\epsilon_{f p c t}
$$

where $\hat{q}_{f p c t} \equiv \hat{\epsilon}_{f p c t} /(\sigma-1) ; 18$ the country-year fixed effect $\varphi_{c t}$ collects both the destination price index $P_{c t}$ and income $Y_{c t}$; the product fixed effect $\varphi_{p}$ captures the difference in prices and quantities across product categories due to the inherent characteristics of products. The intuition behind this approach is that conditional on price, a variety with a higher quantity is assigned higher quality. ${ }^{19}$ Given the value of the elasticity of substitution $\sigma$, we are able to estimate quality from equation (16). The literature yields various estimates of $\sigma$, for example, Eaton and Kortum (2002) obtain estimates of $\sigma$ in the range 3.44-13.86, with their preferred value being $\sigma=9.28 .{ }^{20}$ Hence, in our estimation, we use $\sigma=6$ and $\sigma=12$. Consequently, the quality-adjusted price is the observed log price less estimated quality.

Second, we report two sets of regression results associated with $\sigma=12$ and $\sigma=6$ in Tables 8 and 9, respectively. We replicate the baseline regressions (specifications 1-5 in Table 3) by replacing export prices with the estimated product quality as dependent variable, and present the

\footnotetext{
${ }^{18}$ According to equation (7), there is positive correlation between quality, $q$, and advertisement, $a$. Then (log) quality can be expressed as a linear function of (log) advertisement. Therefore, including advertisement in measured quality does not change the relationship between estimated quality and credit constraints. Another reason why we do not sort out advertisement from measured quality is lack of data on advertisement or marketing cost.

${ }^{19}$ See Khandelwal, Schott, and Wei (2011) for detailed review of this approach.

${ }^{20}$ Anderson and van Wincoop (2004) survey gravity-type estimates of the Arminton substitution elasticity, and conclude that a reasonable range is $\sigma \in[5,10]$ for samples of developed countries. Waugh (2010) obtain similar estimates based on the sample including both rich and poor countries.
} 
results in the left panels of Tables 8 and 9 (specifications 1-5). We find that the coefficients on external finance dependence are negative, and the coefficients on credit access measures are positive. Hence, quality choice is indeed affected by credit constraints. Moreover, the effect of TFP on quality is also positive. All effects are significant at $1 \%$ level with the predicted signs, which verify the mechanism of quality adjustment.

On the other hand, the right panels of Tables 8 and 9 (specifications 6-10) report the results of modified baseline regressions by replacing export prices with quality-adjusted export prices as dependent variable. According to the predictions of the exogenous-quality model, we expect that higher credit needs increase (quality-adjusted) prices, while a higher level of credit access decreases the optimal prices, and a more productive firm set a lower price. Therefore, we should expect positive coefficients on credit needs, negative coefficients on credit access, and negative coefficients on TFP. In our results, we do find that the coefficients on external finance dependence become significantly positive, and the coefficients on TFP become significantly negative, exactly consistent with the predictions of the exogenous-quality model. It is also worth noting that the coefficients on capital intensity also become significantly negative in most specifications, since capital intensity can be viewed as control variable of production technique beyond the productivity of a firm. As for the credit access measures, among all five measures of credit access, one of them now presents significantly negative effect on quality-adjusted prices. The other four show smaller, less significant positive effect on quality-adjusted prices, compared with the baseline regression results (see specifications (1)-(5) in Table 3). These effects again lend support to the prevalence of endogenous-quality model over the exogenous-quality model.

\subsection{Further Verification of Mechanism of Quality Adjustment}

The baseline results and the results by using estimated quality as dependent variable verify the mechanism of quality adjustment and confirm the predictions of the endogenous-quality model. Note that our model works through the mechanism of quality adjustment only if firms choose optimal quality according to their credit constraints. Optimal prices decrease in credit needs but increase in credit access because the quality adjustment effect dominates the price distortion induced by credit constraints.

In this section, we further test the mechanism of quality adjustment and present evidence of the existence of choice of quality by firms. Our earlier theoretical discussions suggest that in the endogenous-quality model, the choice of product quality is the key element through which optimal prices decrease in credit needs and increase in credit access. Otherwise, if quality is exogenous across firms, the exact opposite effects would occur. 


\subsubsection{Controlling for the Different Dimensions of Quality}

If quality adjustment is indeed a true and important mechanism as shown by our model, we should expect that without controlling for input quality the effects of credit needs, credit access, and even productivity on prices would have been amplified since it is safe to believe that the product quality is highly related with the input quality. We thus run the same regressions as in Table 3 but do not control for (labor) input quality measured by log wage (i.e., we compare the regressions without wage as control variables of input quality with those with wage). Table 10 presents the comparison between two sets of results, namely, with and without controlling for wage. The left panel of Table 10 (specifications 1-5) reports the regression results without controlling for wage, while the right panel (specifications 6-10) presents the baseline regression results with wage as control variable. Comparing the left panel with the right panel, we find that without controlling for input quality, the effects of credit constraints (through either credit access or credit needs) on prices are substantially increased, and the coefficients on TFP almost double. We also conduct another test by comparing the baseline regression results between with and without controlling for the share of college workers in total employees, as this indicator can be viewed as another measure of labor input quality. The same pattern holds as in Table 10: with controlling for labor input quality, the effects of credit constraints on prices significantly reduce, for all measures of credit access and credit needs. ${ }^{21}$

The above exercises provide evidence for the existence of quality adjustment by firms. However, it should be noted that our results only confirm that our story of quality adjustment by firms is consistent with the reality. As it is very unlikely that one can use the input quality to perfectly control for the product quality in empirical investigation, we do not expect the effect of credit constraints on prices to disappear after controlling for different dimensions of labor input quality. Indeed, we expect the effect to remain, but has a smaller magnitude. This is precisely what we observe: the signs of the effects of credit constraints on prices are still consistent with the endogenous-quality model, but the coefficient is smaller in magnitude.

\subsubsection{Effects of Quality Variation across Firms}

Our empirical results above show that predictions from the endogenous-quality model are supported by the data. To further compare the two competing theories based on exogenous- and endogenous-quality models, we ask: compared with the benchmark estimation results (see Table 3), what if quality presents more variation across firms? It is safe to conjecture that in the product categories where there is more quality variation across goods, the firms are more likely to behave according to the endogenous-quality model. Conversely, in the categories where there is less quality variation across firms, we expect that firms are more likely to behave according to

\footnotetext{
${ }^{21}$ To save space, we do not report the results based on with and without controlling for the share of college workers in total employees. The results are available upon request.
} 
the exogenous-quality model. Therefore, if our theory is correct, we should expect that the effects of credit constraints on prices are more pronounced for product categories featuring more quality variation. In other words, in product categories with more quality variation across goods we expect the product prices to be more negatively affected by tighter credit constraints.

To confirm our conjecture, we use the variance of unit value export price charged by different firms for the same HS4-product to proxy for the variation of product quality for that product. Then we rank products according to the variance of their unit value prices (i.e., quality variation) and create a dummy variable which is equal to one if the product's quality variation belongs to the top 50 percentile of quality variation among the whole sample, and equal to zero if it belongs to the bottom 50 percentile. Next we redo the baseline regressions by adding the dummy variable and the interaction between the dummy variable and the measures of credit constraints and report the results in Table 11. Specifications (1)-(5) present the results based on the whole sample, and specifications (6)-(10) report the results after winsorizing the extreme $5 \%$ of total observations to rule out some outliers. ${ }^{22}$

The coefficients on the interaction terms are of special interest to us. We find that the coefficients on the interaction term, ExtFin $\times$ Dummy, are significantly negative, and the coefficients on the interaction between the credit access measures and the dummy variable are significantly positive in most cases. ${ }^{23}$ This implies that firms producing in product categories with more quality variation across goods are more negatively affected by tighter credit constraints. Therefore, this exercise further lends support to the endogenous-quality model versus the exogenous-quality model.

\section{Robustness Checks}

In addition to the tests reported in previous tables, we test a number of other specifications for robustness checks. We find the same patterns of impacts of credit constraints on export prices.

First, the results reported in the main tables are estimated using ordinary trade (as opposed to "processing trade") data as we believe firms doing processing trade behave differently from other firms in their exporting behavior. In our sample, ordinary trade accounts for more than $73 \%$ of total transactions. Thus the results based on ordinary trade in fact reflect the average situation in our sample. However, to be cautious about the effect of credit constraints on export prices in the entire sample, which includes different modes of trade, we include the data for processing trade in the robustness checks and find that all predictions of the endogenous-quality model continue

\footnotetext{
${ }^{22}$ In winsorizing the data, tail values are set equal to some specified percentile of the data. Here, for a $95 \%$ winsorization, the bottom $2.5 \%$ of the values are set equal to the value corresponding to the 2.5 th percentile while the upper $2.5 \%$ of the values are set equal to the value corresponding to the 97.5th percentile.

${ }^{23}$ There is an exception for the coefficient on the interaction between the MNC and the dummy variable. When we do not winsorize the sample, the coefficient on the interaction term was negative at $10 \%$ significance level. However, once we winsorize the sample, this effect becomes not significant.
} 
to hold (see Table 12).

Second, productivity is also estimated using different production functions and using different estimation approaches. With the Olley-Pakes's (1996) method, except for the main results we report, we also estimate TFP with material as an input factor. We find that different TFP estimates do not change our main results of the impact of credit constraints on export prices.

Beyond the O-P method, we report our regression results with labor productivity, without controlling for TFP, and with the TFP computed by Ackerberg et al.'s (2006) approach (ACF hereafter). We use value added per employee to measure labor productivity and report the estimation results in specifications (1)-(5) in Table 13. We find that all the main results are significantly preserved. As productivity merely serves as a control variable when we test the effects of credit constraints on export prices, we also estimate the baseline regression, Equation (13), without controlling for productivity (see specifications (6)-(10) in Table 13). By dropping productivity, we can directly observe the overall impact of credit constraints on prices and we find strong evidence to support the negative impact of credit needs and the positive impact of credit access on export prices. Furthermore, we employ De Loecker and Warzynski's (2012) (henceforth DLW) augmented ACF approach together with the two sets of structural techniques suggested by Olley and Pakes (1996) (henceforth OP) and Levinsohn and Petrin (2003) (henceforth LP). ${ }^{24}$ The difference between the LP- and OP-embedded ACF/DLW approaches depends on whether we use materials or investment to proxy for productivity. We report our regression results with TFP estimates based on both the LP- and OP-embedded ACF approaches in Table 14. Again, the results with both variants of TFP estimates support the predictions of the endogenous-quality model: tighter credit constraints lead to lower export prices.

\section{Conclusion}

In this paper we build a tractable trade model with heterogeneous firms to investigate the impacts of credit constraints (via credit needs and credit access) on optimal export prices. Our model departs from Arkolakis's (2010) by its incorporation of endogenous product quality and credit constraints. The endogenous determination of product quality is key to our model. As firms endogenously choose product quality in the production of goods according to the productivity and the credit constraints they face, tighter credit constraints induce firms to choose lower product quality. We call this the quality adjustment effect. When the quality adjustment effect dominates the price distortion effect induced by credit constraints, optimal prices decrease with tighter credit constraints. On the contrary, if quality is exogenous across firms, the exact opposite effects would hold, i.e., the optimal prices would decrease with productivity and increase with tighter credit con-

\footnotetext{
${ }^{24}$ We follow DLW and ACF closely by using a value added translog production function $y=\beta_{l} l+\beta_{k} k+\beta_{l l} l^{2}+$ $\beta_{k k} k^{2}+\beta_{l k} l k+\omega+\varepsilon$, where $\omega$ is productivity, and $\varepsilon$ is error term (see equation (10) in De Loecker and Warzynski (2012).
} 
straints. These contrasting empirical implications enable us to test empirically the endogenousquality model against the exogenous-quality model.

To test the predictions of the two competing theories, we use different types of bank loans and firm ownership to proxy for different levels of credit access and employ external finance dependence, $R \& D$ intensity, inventory-to-sales ratio, and asset tangibility to proxy for credit needs. Our empirical results show that all predictions from the endogenous-quality model are confirmed at $1 \%$ significance level, implying that the endogenous-quality model prevails. Interestingly, we also find evidence to support the exogenous-quality model by using quality-adjusted prices, which, again, verifies the mechanism of quality adjustment in the endogenous-quality model.

The main contribution of this paper is to offer both a theory and the empirical evidence concerning the impacts of credit constraints on export prices set by firms. Our paper contributes to the emerging literature on credit constraints and trade by linking credit constraints with firm attributes and actions such as productivity, quality choice, and optimal export prices. Our paper also contributes to the vast quality-and-trade literature in providing empirical evidence in support of the endogenous-quality model.

There are undoubtedly some limitations to our present study. One concern is that, like the previous studies of credit constraints, we aggregate credit needs measures at the 2-digit industry level, without taking into account the distribution effects of credit constraints within an industry. As Chaney (2005) indicates, intra-industry distribution of liquidity constraints may impact exporting behavior. It is reasonable to suspect that there are significant impacts of the distribution of credit constraints on export prices as well as on the relationship between productivity and export prices. A thorough analysis of this issue would be fruitful and is left to future research. Another limitation is that our empirical findings and the theoretical propositions both build upon exogenous credit constraints. If credit constraints are endogenously determined, some dynamic effects may emerge, and this would affect the exit and entry of firms. In the present paper, our database does not include non-exporting firms because data on domestic prices are not available at the firm-product level. If domestic-price data are available, we should be able to construct a model to analyze the difference in firm dynamics between exporters and non-exporters with respect to the impacts of credit constraints. For this endeavor, it would be useful to acquire and construct firm- and product-level data on prices in domestic markets.

\section{References}

Ackerberg, Daniel, Kevin Caves, and Garth Frazer, "Structural identification of production functions," MPRA Paper 38349, University Library of Munich, Germany December 2006.

Amiti, Mary and David E. Weinstein, "Exports and Financial Shocks," The Quarterly Journal of Economics, 2011, 126 (4), 1841-1877. 
- and Jozef Konings, "Trade Liberalization, Intermediate Inputs, and Productivity: Evidence from Indonesia," American Economic Review, December 2007, 97 (5), 1611-1638.

Anderson, James E. and Eric van Wincoop, "Trade Costs," Journal of Economic Literature, September 2004, 42 (3), 691-751.

Antoniades, Alexis, "Heterogeneous Firms, Quality and Trade," Unpublished Manuscript, Princeton University and Georgetown University November 2012.

Arkolakis, Costas, "Market Penetration Costs and the New Consumers Margin in International Trade," Journal of Political Economy, 2010, 118 (6), 1151 - 1199.

Baldwin, Richard and James Harrigan, "Zeros, Quality, and Space: Trade Theory and Trade Evidence," American Economic Journal: Microeconomics, May 2011, 3 (2), 60-88.

Boyreau-Debray, Genevieve and Shang-Jin Wei, "Pitfalls of a State-Dominated Financial System: The Case of China," NBER Working Papers 11214, National Bureau of Economic Research, Inc March 2005.

Brandt, Loren, Johannes Van Biesebroeck, and Yifan Zhang, "Creative Accounting or Creative Destruction? Firm-level Productivity Growth in Chinese Manufacturing," Journal of Development Economics, 2012, 97 (2), 339-351.

Butters, Gerard R, "Equilibrium Distributions of Sales and Advertising Prices," Review of Economic Studies, October 1977, 44 (3), 465-91.

Cai, Hongbin and Qiao Liu, "Competition and Corporate Tax Avoidance: Evidence from Chinese Industrial Firms," Economic Journal, 04 2009, 119 (537), 764-795.

Chaney, Thomas, "Liquidity Constrained Exporters," Unpublished Manuscript, University of Chicago 2005.

Chor, Davin and Kalina Manova, "Off the Cliff and Back? Credit Conditions and International Trade during the Global Financial Crisis," Journal of International Economics, 2012, 87 (1), 117133.

Claessens, Stijn and Luc Laeven, "Financial Development, Property Rights, and Growth," Journal of Finance, December 2003, 58 (6), 2401-2436.

Dinlersoz, Emin M. and Mehmet Yorukoglu, "Informative advertising by heterogeneous firms," Information Economics and Policy, June 2008, 20 (2), 168-191.

Dollar, David and Shang-Jin Wei, "Das (Wasted) Kapital: Firm Ownership and Investment Efficiency in China," NBER Working Papers 13103, National Bureau of Economic Research, Inc May 2007. 
Eaton, Jonathan and Samuel Kortum, "Technology, Geography, and Trade," Econometrica, September 2002, 70 (5), 1741-1779.

Feenstra, Robert C., Zhiyuan Li, and Miaojie Yu, "Exports and Credit Constraints Under Incomplete Information: Theory and Evidence from China," NBER Working Papers 16940, National Bureau of Economic Research, Inc April 2011.

Gervais, Antoine, "Product Quality, Firm Heterogeneity and International Trade," Unpublished Manuscript, University of Notre Dame June 2011.

Grossman, Gene M and Carl Shapiro, "Informative Advertising with Differentiated Products," Review of Economic Studies, January 1984, 51 (1), 63-81.

Hallak, Juan Carlos, "A Product-Quality View of the Linder Hypothesis," The Review of Economics and Statistics, 09 2010, 92 (3), 453-466.

- and Jagadeesh Sivadasan, "Firms' Exporting Behavior under Quality Constraints," Unpublished Manuscript September 2011.

Johnson, Robert C., "Trade and prices with heterogeneous firms," Journal of International Economics, $2012,86(1), 43-56$.

Khandelwal, Amit K., Peter K. Schott, and Shang-Jin Wei, "Trade Liberalization and Embedded Institutional Reform: Evidence from Chinese Exporters," NBER Working Papers 17524, National Bureau of Economic Research, Inc October 2011.

Kroszner, Randall S., Luc Laeven, and Daniela Klingebiel, "Banking crises, financial dependence, and growth," Journal of Financial Economics, April 2007, 84 (1), 187-228.

Kugler, Maurice and Eric Verhoogen, "Prices, Plant Size, and Product Quality," Review of Economic Studies, forthcoming.

Levinsohn, James and Amil Petrin, "Estimating Production Functions Using Inputs to Control for Unobservables," The Review of Economic Studies, 2003, 70 (2), pp. 317-341.

Loecker, Jan De and Frederic Warzynski, "Markups and Firm-Level Export Status," American Economic Review, October 2012, 102 (6), 2437-71.

Lu, Jiangyong, Yi Lu, and Zhigang Tao, "Exporting behavior of foreign affiliates: Theory and evidence," Journal of International Economics, July 2010, 81 (2), 197-205.

Manova, Kalina, "Credit Constraints, Heterogeneous Firms, and International Trade," Review of Economic Studies, forthcoming. 
- and Zhiwei Zhang, "Export Prices Across Firms and Destinations," The Quarterly Journal of Economics, forthcoming.

_ , Shang-Jin Wei, and Zhiwei Zhang, "Firm Exports and Multinational Activity Under Credit Constraints," NBER Working Papers 16905, National Bureau of Economic Research, Inc 2011.

Melitz, Marc J., “The Impact of Trade on Intra-Industry Reallocations and Aggregate Industry Productivity," Econometrica, November 2003, 71 (6), 1695-1725.

Minetti, Raoul and Susan Chun Zhu, "Credit constraints and firm export: Microeconomic evidence from Italy," Journal of International Economics, March 2011, 83 (2), 109-125.

Olley, G. Steven and Ariel Pakes, "The Dynamics of Productivity in the Telecommunications Equipment Industry," Econometrica, 1996, 64 (6), pp. 1263-1297.

Phillips, Gordon M. and Giorgo Sertsios, "How Do Firm Financial Conditions Affect Product Quality and Pricing?," NBER Working Papers 17233, National Bureau of Economic Research, Inc July 2011.

Rajan, Raghuram G and Luigi Zingales, "Financial Dependence and Growth," American Economic Review, June 1998, 88 (3), 559-86.

Riedel, James, Jing Jin, and Jian Gao, "Overview of Economic Reforms and Outcomes," in "How China Grows: Investment, Finance, and Reform," Princeton University Press, October 2007.

Song, Zheng, Kjetil Storesletten, and Fabrizio Zilibotti, “Growing Like China,” American Economic Review, February 2011, 101 (1), 196-233.

Stegeman, Mark, "Advertising in Competitive Markets," American Economic Review, March 1991, 81 (1), 210-23.

Sutton, John, Sunk Costs and Market Structure: Price Competition, Advertising, and the Evolution of Concentration, Vol. 1 of MIT Press Books, The MIT Press, December 2007.

Verhoogen, Eric A., “Trade, Quality Upgrading, and Wage Inequality in the Mexican Manufacturing Sector," The Quarterly Journal of Economics, 05 2008, 123 (2), 489-530.

Waugh, Michael E., "International Trade and Income Differences," American Economic Review, December 2010, 100 (5), 2093-2124.

Yu, Miaojie, "Processing Trade, Firms Productivity, and Tariff Reductions : Evidence from Chinese Products," CTRG Working Paper Series 2011/014, China Trade Research Group January 2011. 


\section{Appendix}

\section{A The derivation for First-Order Condition: equation (4), (5) and (6) [For referees' reference only. Not for publication]}

The optimization problem of a firm with productivity $\phi$, credit access $\theta$, and credit needs $d$ is:

$$
\begin{gathered}
\max _{p, q, a}\left(p-\frac{\tau q^{\alpha}}{\phi}\right)(q a)^{\sigma-1} \frac{p^{-\sigma}}{P^{1-\sigma}} Y-f_{x} \frac{a^{1+\epsilon}}{1+\epsilon}-f_{d} q^{\beta} \\
\text { s.t. } \theta\left[\left(p-(1-d) \frac{\tau q^{\alpha}}{\phi}\right)(q a)^{\sigma-1} \frac{p^{-\sigma}}{P^{1-\sigma}} Y-(1-d)\left(f_{x} \frac{a^{1+\epsilon}}{1+\epsilon}+f_{d} q^{\beta}\right)\right] \\
\geq d\left[\frac{\tau q^{\alpha}}{\phi}(q a)^{\sigma-1} \frac{p^{-\sigma}}{P^{1-\sigma}} Y+f_{x} \frac{a^{1+\epsilon}}{1+\epsilon}+f_{d} q^{\beta}\right]
\end{gathered}
$$

Let $\lambda \geq 0$ denote the Lagrange multiplier. Then, the Lagrange function is given by:

$$
\begin{gathered}
L(p, q, a, \lambda)=\left(p-\frac{\tau q^{\alpha}}{\phi}\right)(q a)^{\sigma-1} \frac{p^{-\sigma}}{P^{1-\sigma}} Y-f_{x} \frac{a^{1+\epsilon}}{1+\epsilon}-f_{d} q^{\beta} \\
+\lambda\left[\left(p-\left(1+\frac{d}{\theta}-d\right) \frac{\tau q^{\alpha}}{\phi}\right)(q a)^{\sigma-1} \frac{p^{-\sigma}}{P^{1-\sigma}} Y-\left(1+\frac{d}{\theta}-d\right)\left(f_{x} \frac{a^{1+\epsilon}}{1+\epsilon}+f_{d} q^{\beta}\right)\right]
\end{gathered}
$$

which is equivalent to:

$$
\left[p-\left(1+d \frac{(1-\theta) \lambda}{\theta(1+\lambda)}\right) \frac{\tau q^{\alpha}}{\phi}\right](q a)^{\sigma-1} \frac{p^{-\sigma}}{P^{1-\sigma}} Y-\left(1+d \frac{(1-\theta) \lambda}{\theta(1+\lambda)}\right)\left(f_{x} \frac{a^{1+\epsilon}}{1+\epsilon}+f_{d} q^{\beta}\right)
$$

Totally differentiating the previous expression (17) with respect to price $p$, quality $q$, and advertisement $a$ yields:

$$
\begin{gathered}
(\sigma-1)(q a)^{\sigma-1} \frac{p^{1-\sigma}}{P^{1-\sigma}} Y=\sigma\left(1+d \frac{(1-\theta) \lambda}{\theta(1+\lambda)}\right) \frac{\tau q^{\alpha}}{\phi}(q a)^{\sigma-1} \frac{p^{-\sigma}}{P^{1-\sigma}} Y \\
(\sigma-1)\left[p-\left(1+d \frac{(1-\theta) \lambda}{\theta(1+\lambda)}\right) \frac{\tau q^{\alpha}}{\phi}\right](q a)^{\sigma-1} \frac{p^{-\sigma}}{P^{1-\sigma}} Y-\alpha\left(1+d \frac{(1-\theta) \lambda}{\theta(1+\lambda)}\right) \frac{\tau q^{\alpha}}{\phi}(q a)^{\sigma-1} \frac{p^{-\sigma}}{P^{1-\sigma}} Y \\
=\left(1+d \frac{(1-\theta) \lambda}{\theta(1+\lambda)}\right) \beta f_{d} q^{\beta} \\
{\left[p-\left(1+d \frac{(1-\theta) \lambda}{\theta(1+\lambda)}\right) \frac{\tau q^{\alpha}}{\phi}\right](\sigma-1)(q a)^{\sigma-1} \frac{p^{-\sigma}}{P^{1-\sigma}} Y=\left(1+d \frac{(1-\theta) \lambda}{\theta(1+\lambda)}\right) f_{x} a^{1+\epsilon}}
\end{gathered}
$$

According to equation (18), we derive:

$$
p=\frac{\sigma}{\sigma-1}\left(1+d \frac{(1-\theta) \lambda}{\theta(1+\lambda)}\right) \frac{\tau q^{\alpha}}{\phi}
$$


which is equation (4). Substituting equation (21) into equation (19), we derive:

$$
\begin{aligned}
& \left(\frac{\sigma-1}{\sigma}-\alpha \frac{\sigma-1}{\sigma}\right)(q a)^{\sigma-1} \frac{p^{1-\sigma}}{P^{1-\sigma}} Y=\left(1+d \frac{(1-\theta) \lambda}{\theta(1+\lambda)}\right) \beta f_{d} q^{\beta} \\
& \Leftrightarrow(q a)^{\sigma-1} \frac{p^{1-\sigma}}{P^{1-\sigma}} Y=\frac{\sigma \beta}{(1-\alpha)(\sigma-1)}\left(1+d \frac{(1-\theta) \lambda}{\theta(1+\lambda)}\right) f_{d} q^{\beta}
\end{aligned}
$$

which is equation (5). Substituting equation (21) into equation (20), we derive:

$$
\begin{gathered}
\frac{\sigma-1}{\sigma}(q a)^{\sigma-1} \frac{p^{1-\sigma}}{P^{1-\sigma}} Y=\left(1+d \frac{(1-\theta) \lambda}{\theta(1+\lambda)}\right) f_{x} a^{1+\epsilon} \\
\Leftrightarrow(q a)^{\sigma-1} \frac{p^{1-\sigma}}{P^{1-\sigma}} Y=\frac{\sigma}{\sigma-1}\left(1+d \frac{(1-\theta) \lambda}{\theta(1+\lambda)}\right) f_{x} a^{1+\epsilon}
\end{gathered}
$$

which is equation (6).

\section{B Proof of Proposition 5 (Quality is exogenous)}

When quality is exogenous, the optimization problem of a firm with productivity $\phi$, credit access $\theta$, and credit needs $d$ becomes:

$$
\begin{gathered}
\max _{p, a}\left(p-\frac{\tau}{\phi}\right) \frac{a^{\sigma-1} p^{-\sigma}}{P^{1-\sigma}} Y-f_{x} \frac{a^{1+\epsilon}}{1+\epsilon}-f_{d} \\
\text { s.t. } \theta\left[\left(p-(1-d) \frac{\tau}{\phi}\right) \frac{a^{\sigma-1} p^{-\sigma}}{P^{1-\sigma}} Y-(1-d)\left(f_{x} \frac{a^{1+\epsilon}}{1+\epsilon}+f_{d}\right)\right] \\
\geq d\left(\frac{\tau}{\phi} \frac{a^{\sigma-1} p^{-\sigma}}{P^{1-\sigma}} Y+f_{x} \frac{a^{1+\epsilon}}{1+\epsilon}+f_{d}\right)
\end{gathered}
$$

Solving this optimization problem with respect to price $p$, and advertisement $a$ yields:

$$
\begin{aligned}
p & =\frac{\sigma}{\sigma-1}\left(1+d \frac{(1-\theta) \lambda}{\theta(1+\lambda)}\right) \frac{\tau}{\phi} \\
\frac{a^{\sigma-1} p^{1-\sigma}}{P^{1-\sigma}} Y & =\frac{\sigma}{\sigma-1}\left(1+d \frac{(1-\theta) \lambda}{\theta(1+\lambda)}\right) f_{x} a^{1+\epsilon}
\end{aligned}
$$

where $\lambda$ is the Lagrangian multiplier associated with budget constraint condition (23). Next, we analyze this optimization problem for two cases.

Case A.1: The budget constraint (23) is binding.

According to the equations (24) and (25), we have:

$$
\left(\frac{\sigma}{\sigma-1} \frac{\tau}{\phi}\right)^{1-\sigma} \frac{Y}{P^{1-\sigma}}=\frac{\sigma}{\sigma-1}\left(1+d \frac{(1-\theta) \lambda}{\theta(1+\lambda)}\right)^{\sigma} a^{(\sigma-1) \Theta}
$$


Figure 2: When quality is exogenous

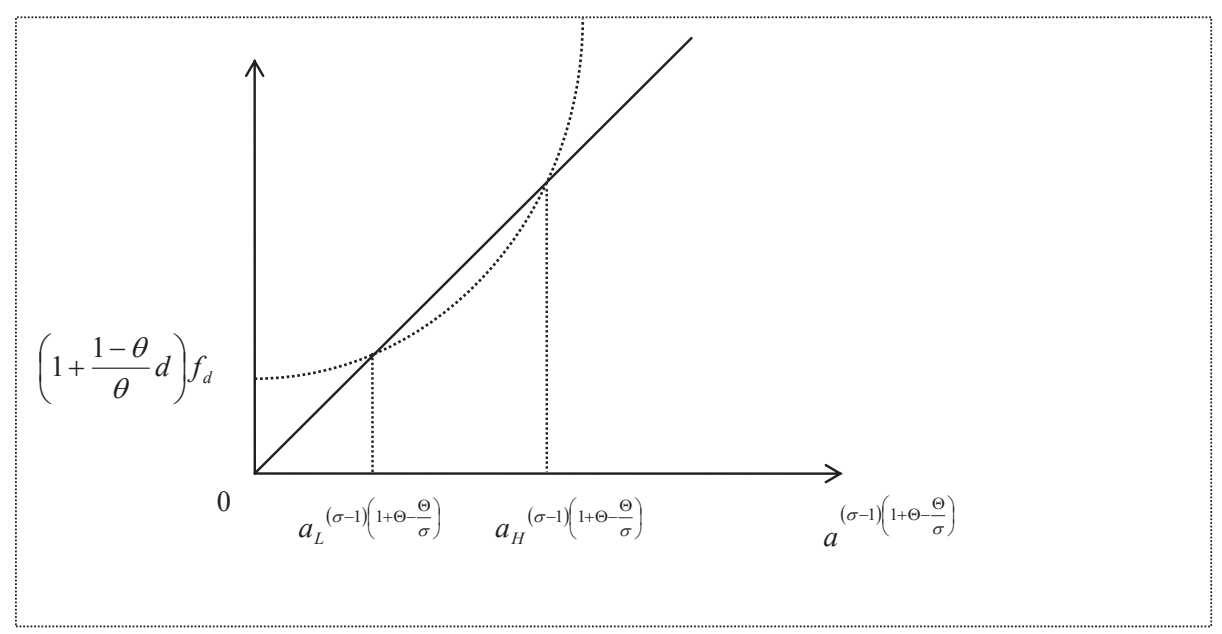

where $1+\Theta \equiv \frac{1+\epsilon}{\sigma-1}$. The budget constraint (23), together with equations (24) and (25), imply:

$$
\frac{\sigma}{\sigma-1}\left(1+d \frac{(1-\theta) \lambda}{\theta(1+\lambda)}\right) f_{x} a^{(\sigma-1)(1+\Theta)} \geq\left(1-d+\frac{d}{\theta}\right)\left(f_{x} a^{(\sigma-1)(1+\Theta)}+f_{x} \frac{a^{(\sigma-1)(1+\Theta)}}{(\sigma-1)(1+\Theta)}+f_{d}\right)
$$

Hence, (26) and (27) yield

$$
\left(\frac{\tau}{\phi}\right)^{\frac{1-\sigma}{\sigma}}\left(\frac{Y}{P^{1-\sigma}}\right)^{\frac{1}{\sigma}} a^{(\sigma-1)\left(1+\Theta-\frac{\Theta}{\sigma}\right)} \geq\left(1-d+\frac{d}{\theta}\right)\left(\frac{\sigma+\sigma \Theta-\Theta}{(\sigma-1)(1+\Theta)} f_{x} a^{(\sigma-1)(1+\Theta)}+f_{d}\right)
$$

This equation implies that the budget constraint (23) holds only in the zone $a \in\left[a_{L}, a_{H}\right]$ as shown in Figure 2. If the first-best solution does not belong in this zone, then budget constraint is binding. Now, the firm's profit satisfies:

$$
\begin{aligned}
\left(p-\frac{\tau}{\phi}\right) \frac{a^{\sigma-1} p^{-\sigma}}{P^{1-\sigma}} Y-f_{x} \frac{a^{1+\epsilon}}{1+\epsilon}-f_{d} & =\frac{1-\theta}{\theta} d\left(\frac{\tau}{\phi} \frac{a^{\sigma-1} p^{-\sigma}}{P^{1-\sigma}} Y+f_{x} \frac{a^{(\sigma-1)(1+\Theta)}}{(\sigma-1)(1+\Theta)}+f_{d}\right) \\
& =\frac{1-\theta}{\theta} d\left(f_{x} a^{(\sigma-1)(1+\Theta)}+f_{x} \frac{a^{(\sigma-1)(1+\Theta)}}{(\sigma-1)(1+\Theta)}+f_{d}\right)
\end{aligned}
$$

Then the firm will choose its second-best solution $a_{H}$ in order to maximize its profit. We use Figure 2 to illustrate: In Figure 2, the horizontal axis denotes $a^{(\sigma-1)\left(1+\Theta-\frac{\Theta}{\sigma}\right)}$ and the vertical axis denotes any multiplicative scale of $a^{(\sigma-1)\left(1+\Theta-\frac{\Theta}{\sigma}\right)}$. The dotted curve represents the right-handside of inequality (28) with intercept $\left(1+\frac{1-\theta}{\theta}\right) f_{d}$. The solid line represents the left-hand-side of inequality (28). As shown in Figure 2, given firm's productivity $\phi$, the dotted curve in Figure 2 will shift upward as credit needs $d$ increases or credit access $\theta$ decreases. As a result, the optimal demand shifter induced by advertisement will decline. Meanwhile, the optimal price distorted by $1+d \frac{(1-\theta) \lambda}{\theta(1+\lambda)}$ rises according to equation (26). Therefore, tighter credit constraints (i.e., a higher $d$ or 
a lower $\theta$ ) lead to higher prices when quality is exogenous. Given credit access $\theta$ and credit needs $d$, the solid line in Figure 2 will shift upward when productivity $\phi$ increases. This yields a higher $a_{H}$, which implies that the distortion $1+d \frac{(1-\theta) \lambda}{\theta(1+\lambda)}$ decreases according to equation (27). Hence, the optimal price will decrease in productivity according to the pricing rule (24).

Case A.2: The budget constraint (23) is nonbinding. There is no distortion caused by credit constraint in price setting and the optimal pricing rule is given by $p=\frac{\sigma}{\sigma-1} \frac{\tau}{\phi}$. Hence, the optimal price is unrelated to credit constraint and decreases in productivity. QED.

\section{Proof of Proposition 6 (Only fixed costs are financed by outside capital)}

\section{C1. Under endogenous quality}

Now, the optimization problem of a firm with productivity $\phi$, credit access $\theta$, and credit needs $d$ becomes:

$$
\begin{gathered}
\max _{p, q, a}\left(p-\frac{\tau q^{\alpha}}{\phi}\right)(q a)^{\sigma-1} \frac{p^{-\sigma}}{P^{1-\sigma}} Y-f_{x} \frac{a^{1+\epsilon}}{1+\epsilon}-f_{d} q^{\beta} \\
\text { s.t. } \theta\left[\left(p-\frac{\tau q^{\alpha}}{\phi}\right)(q a)^{\sigma-1} \frac{p^{-\sigma}}{P^{1-\sigma}} Y-(1-d)\left(f_{x} \frac{a^{1+\epsilon}}{1+\epsilon}+f_{d} q^{\beta}\right)\right] \geq d\left(f_{x} \frac{a^{1+\epsilon}}{1+\epsilon}+f_{d} q^{\beta}\right)
\end{gathered}
$$

Solving this optimization problem with respect to price $p$, quality $q$, and advertisement $a$ yields

$$
\begin{aligned}
p & =\frac{\sigma}{\sigma-1} \frac{\tau q^{\alpha}}{\phi} \\
(q a)^{\sigma-1} \frac{p^{1-\sigma}}{P^{1-\sigma}} Y & =\frac{\sigma \beta}{(1-\alpha)(\sigma-1)}\left(1+d \frac{(1-\theta) \lambda}{\theta(1+\lambda)}\right) f_{d} q^{\beta} \\
(q a)^{\sigma-1} \frac{p^{1-\sigma}}{P^{1-\sigma}} Y & =\frac{\sigma}{\sigma-1}\left(1+d \frac{(1-\theta) \lambda}{\theta(1+\lambda)}\right) f_{x} a^{1+\epsilon}
\end{aligned}
$$

where $\lambda$ is the Lagrangian multiplier associated with budget constraint (30). Then equations (32) and (33) imply that the optimal volume of advertisement, $a$, is positively correlated with product quality, $q$.

$$
q^{\beta}=\frac{1-\alpha}{\beta f_{d}} f_{x} a^{1+\epsilon}
$$

This expression, together with budget constraint (30) and conditions (31) and (32), imply

$$
\Lambda\left(1+d \frac{(1-\theta) \lambda}{1+\theta \lambda}\right) \geq\left(1-d+\frac{d}{\theta}\right)\left(\frac{\Lambda}{1+\Theta}+1\right)
$$

Then we also analyze two cases.

Case B.1: The budget constraint (30) is binding. Now, equation (30), together with (31) and 
(34), imply:

$$
\left(1-d+\frac{d}{\theta}\right)\left(\frac{\Lambda}{1+\Theta}+1\right) \sigma f_{d} q^{\frac{\Theta \beta}{1+\Theta}-(1-\alpha)(\sigma-1)}=\left(\frac{(\sigma-1) \Lambda f_{d}}{f_{x}}\right)^{\frac{1}{1+\Theta}}\left(\frac{\sigma}{\sigma-1} \frac{\tau}{\phi}\right)^{1-\sigma} \frac{Y}{P^{1-\sigma}}
$$

Under the condition (i) $\Theta \beta>(1-\alpha)(\sigma-1)(1+\Theta)$, there is positive correlation between firm productivity $\phi$ and quality $q$. Combining the equations (35) and (31), the optimal price in this case is given by:

$$
p=\left(\frac{1}{\left(1-d+\frac{d}{\theta}\right)\left(\frac{\Lambda}{1+\Theta}+1\right) \sigma f_{d}}\right)^{\Psi}\left(\frac{(\sigma-1) \Lambda f_{d}}{f_{x}}\right)^{\frac{\Psi}{1+\Theta}}\left(\frac{\sigma}{\sigma-1} \frac{\tau}{\phi}\right)^{1+(1-\sigma) \Psi}\left(\frac{Y}{P^{1-\sigma}}\right)^{\Psi}
$$

where $\Psi=\frac{\alpha(1+\Theta)}{\Theta \beta-(1-\alpha)(\sigma-1)(1+\Theta)}$. Under the two conditions: (i) $\Theta \beta>(1-\alpha)(\sigma-1)(1+\Theta)$; and (ii) $(\sigma-1)(1+\Theta)-\Theta \beta>0$, the optimal price increases in productivity. In addition, less credit access (i.e., a lower $\theta$ ) or higher credit needs (i.e., a higher $d$ ) leads to lower prices.

Case B.2: The budget constraint (30) is nonbinding. Based on the same derivation, the optimal pricing rule also satisfies:

$$
p=\left(\sigma \Lambda f_{d}\right)^{-\Psi}\left(\frac{(\sigma-1) \Lambda f_{d}}{f_{x}}\right)^{\Psi /(1+\Theta)}\left(\frac{\sigma}{\sigma-1} \frac{\tau}{\phi}\right)^{1+(1-\sigma) \Psi}\left(\frac{Y}{P^{1-\sigma}}\right)^{\Psi}
$$

Hence under the conditions (i) $\Theta \beta>(1-\alpha)(\sigma-1)(1+\Theta)$ and (ii) $(\sigma-1)(1+\Theta)-\Theta \beta>0$, the optimal price increases in productivity. However, the optimal price is unrelated to credit constraints.

\section{C2. Under exogenous quality}

Then, the optimal price satisfies:

$$
p=\frac{\sigma}{\sigma-1} \frac{\tau}{\phi}
$$

Hence, the optimal price decreases in productivity. In addition, the optimal price is independent of credit constraints. QED.

\section{Tables}


Table 1: External Finance Dependence: US vs. China

\begin{tabular}{|c|c|c|c|c|c|}
\hline Industry Name (US) & ISIC & value & value & $\mathrm{CIC}$ & Industry Name (CHN) \\
\hline Tobacco & 314 & -1.14 & -2.59 & 35 & General Purpose Machinery \\
\hline Leather products & 323 & -0.95 & -1.54 & 16 & Tobacco \\
\hline Footwear & 324 & -0.74 & -1.34 & 41 & $\begin{array}{l}\text { Measuring Instruments and Machinery for } \\
\text { Cultural Activity and Office Work }\end{array}$ \\
\hline Printing and Publishing & 342 & -0.42 & -1.32 & 18 & Textile Wearing Apparel, Footwear, and Caps \\
\hline Pottery, china, earthenware & 361 & -0.41 & -1.11 & 19 & Leather, Fur, Feather and Related Products \\
\hline Furniture & 332 & -0.38 & -0.93 & 34 & Metal Products \\
\hline Paper products & 341 & -0.35 & -0.8 & 23 & Printing, Reproduction of Recording Media \\
\hline Other chemical products & 352 & -0.3 & -0.72 & 20 & $\begin{array}{l}\text { Processing of Timber, Manufacture of Wood, } \\
\text { Bamboo, Rattan, Palm, and Straw Products }\end{array}$ \\
\hline Non-metallic products & 369 & -0.29 & -0.72 & 15 & Beverages \\
\hline Fabricated metal products & 381 & -0.25 & -0.72 & 37 & Transport Equipment \\
\hline Apparel & 322 & -0.21 & -0.65 & 21 & Furniture \\
\hline Industrial chemicals & 3511 & -0.19 & -0.62 & 42 & Artwork and Other Manufacturing \\
\hline Food products & 311 & -0.15 & -0.48 & 17 & Textile \\
\hline Non-ferrous metals & 372 & -0.12 & -0.47 & 30 & Plastics \\
\hline Transport equipment & 384 & -0.08 & -0.47 & 13 & Processing of Food from Agricultural Products \\
\hline Machinery, except electrical & 382 & -0.04 & -0.44 & 27 & Medicines \\
\hline Petroleum refineries & 353 & -0.02 & -0.44 & 39 & Electrical Machinery and Equipment \\
\hline Plastic products & 356 & -0.02 & -0.41 & 28 & Chemical Fibers \\
\hline Rubber products & 355 & -0.02 & -0.4 & 24 & Articles For Culture, Education and Sport Activity \\
\hline Textiles & 321 & 0.01 & -0.32 & 14 & Foods \\
\hline Beverages & 313 & 0.03 & -0.29 & 31 & Non-metallic Mineral Products \\
\hline Synthetic resins & 3513 & 0.03 & -0.27 & 36 & Special Purpose Machinery \\
\hline Glass products & 362 & 0.03 & -0.26 & 29 & Rubber \\
\hline Iron and steel & 371 & 0.05 & -0.23 & 26 & Raw Chemical Materials and Chemical Products \\
\hline Wood products & 331 & 0.05 & -0.1 & 33 & Smelting and Pressing of Non-ferrous Metals \\
\hline Petroleum and coal products & 354 & 0.13 & 0.02 & 40 & $\begin{array}{l}\text { Communication Equipment, Computers } \\
\text { and Other Electronic Equipment }\end{array}$ \\
\hline Electrical machinery & 383 & 0.24 & 0.07 & 22 & Paper and Paper Products \\
\hline Other manufactured products & 390 & 0.28 & 0.33 & 32 & Smelting and Pressing of Ferrous Metals \\
\hline \multirow[t]{2}{*}{ Professional and scientific equipment } & 385 & 0.72 & 0.62 & 25 & $\begin{array}{l}\text { Processing of Petroleum, Coking, } \\
\text { Processing of Nuclear Fuel }\end{array}$ \\
\hline & mean & -0.16 & -0.57 & mean & \\
\hline
\end{tabular}


Table 2: Total Factor Productivity of Chinese Firms (2000-2006)

\begin{tabular}{|c|c|c|}
\hline Chinese Industrial Classification (2-digit code): & Labor coeff & Capital coeff \\
\hline Processing of Food from Agricultural Products (13) & $0 . .5136$ & 0.2834 \\
\hline Manufacture of Foods (14) & 0.5717 & 0.3562 \\
\hline Manufacture of Beverages (15) & 0.5427 & 0.4335 \\
\hline Manufacture of Tobacco (16) & 0.4559 & 0.6209 \\
\hline Manufacture of Textile (17) & 0.4710 & 0.2279 \\
\hline Manufacture of Textile Wearing Apparel, Footware, and Caps (18) & 0.5505 & 0.2313 \\
\hline Manufacture of Leather, Fur, Feather and Related Products(19) & 0.4801 & 0.2476 \\
\hline $\begin{array}{l}\text { Processing of Timber, Manufacture of Wood, Bamboo, Rattan, } \\
\text { Palm, and Straw Products (20) }\end{array}$ & 0.5021 & 0.2893 \\
\hline Manufacture of Furniture (21) & 0.5871 & 0.1442 \\
\hline Manufacture of Paper and Paper Products (22) & 0.4960 & 0.3371 \\
\hline Printing, Reproduction of Recording Media (23) & 0.4939 & 0.2791 \\
\hline Manufacture of Articles For Culture, Education and Sport Activity (24) & 0.5036 & 0.1299 \\
\hline Processing of Petroleum, Coking, Processing of Nuclear Fuel (25) & 0.3238 & 0.4445 \\
\hline Manufacture of Raw Chemical Materials and Chemical Products (26) & 0.3799 & 0.3485 \\
\hline Manufacture of Medicines (27) & 0.5082 & 0.2284 \\
\hline Manufacture of Chemical Fibers(28) & 0.5118 & 0.4046 \\
\hline Manufacture of Rubber (29) & 0.4403 & 0.1651 \\
\hline Manufacture of Plastics (30) & 0.4601 & 0.2859 \\
\hline Manufacture of Non-metallic Mineral Products (31) & 0.4173 & 0.2873 \\
\hline Smelting and Pressing of Ferrous Metals (32) & 0.5029 & 0.3298 \\
\hline Smelting and Pressing of Non-ferrous Metals (33) & 0.4349 & 0.3244 \\
\hline Manufacture of Metal Products (34) & 0.4443 & 0.3000 \\
\hline Manufacture of General Purpose Machinery (35) & 0.4686 & 0.3035 \\
\hline Manufacture of Special Purpose Machinery (36) & 0.4949 & 0.3610 \\
\hline Manufacture of Transport Equipment (37) & 0.5488 & 0.3269 \\
\hline Manufacture of Electrical Machinery and Equipment (39) & 0.4873 & 0.3097 \\
\hline $\begin{array}{l}\text { Manufacture of Communication Equipment, Computers and } \\
\text { Other Electronic Equipment (40) }\end{array}$ & 0.5327 & 0.2537 \\
\hline $\begin{array}{l}\text { Manufacture of Measuring Instruments and Machinery for Cultural } \\
\text { Activity and Office Work (41) }\end{array}$ & 0.4310 & 0.2347 \\
\hline Manufacture of Artwork and Other Manufacturing (42) & 0.4649 & 0.2000 \\
\hline
\end{tabular}


Table 3: Credit Constraints and Export Prices across Product-Destination: External Finance Dependence and R\&D

\begin{tabular}{|c|c|c|c|c|c|c|c|c|c|c|}
\hline Regressor: & (1) & (2) & (3) & (4) & (5) & (6) & (7) & (8) & (9) & $(10)$ \\
\hline \multirow[t]{2}{*}{$\log (\mathrm{TFP})$} & $0.060^{* * *}$ & $0.058^{* * *}$ & $0.059^{* * *}$ & $0.029^{* * *}$ & $0.077^{* * *}$ & $0.060^{* * *}$ & $0.058^{* * *}$ & $0.059^{* * *}$ & $0.029^{* * *}$ & $0.077^{* * *}$ \\
\hline & $(0.002)$ & $(0.002)$ & $(0.002)$ & $(0.004)$ & $(0.004)$ & $(0.002)$ & $(0.002)$ & $(0.002)$ & $(0.004)$ & $(0.004)$ \\
\hline \multirow[t]{2}{*}{$\log ($ Labor $)$} & $0.026^{* * *}$ & $0.024^{* * *}$ & $0.025^{* * *}$ & $-0.020^{* * *}$ & $0.008^{* *}$ & $0.026^{* * *}$ & $0.024^{* * *}$ & $0.026^{* * *}$ & $-0.020^{* * *}$ & $0.007^{* *}$ \\
\hline & $(0.002)$ & $(0.002)$ & $(0.002)$ & $(0.003)$ & $(0.004)$ & $(0.002)$ & $(0.002)$ & $(0.002)$ & $(0.003)$ & $(0.004)$ \\
\hline \multirow[t]{2}{*}{$\log$ (Capitla/Labor) } & $0.043^{* * *}$ & $0.044^{* * *}$ & $0.045^{* * *}$ & $0.020^{* * *}$ & $0.051^{* * *}$ & $0.042^{* * *}$ & $0.043^{* * *}$ & $0.044^{* * *}$ & $0.020^{* * *}$ & $0.050^{* * *}$ \\
\hline & $(0.002)$ & $(0.002)$ & $(0.002)$ & $(0.003)$ & $(0.003)$ & $(0.002)$ & $(0.002)$ & $(0.002)$ & $(0.003)$ & $(0.003)$ \\
\hline \multirow[t]{2}{*}{$\log$ (Wage) } & $0.251^{* * *}$ & $0.277^{* * *}$ & $0.245^{* * *}$ & $0.167^{* * *}$ & $0.305^{* * *}$ & $0.252^{* * *}$ & $0.278^{* * *}$ & $0.246^{* * *}$ & $0.169^{* * *}$ & $0.305^{* * *}$ \\
\hline & $(0.005)$ & $(0.005)$ & $(0.005)$ & $(0.006)$ & $(0.008)$ & $(0.005)$ & $(0.005)$ & $(0.005)$ & $(0.006)$ & $(0.008)$ \\
\hline \multirow[t]{2}{*}{ ExtFin } & $-3.465^{* * *}$ & $-3.484^{* * *}$ & $-3.445^{* * *}$ & $-3.995^{* * *}$ & $-2.959 * * *$ & & & & & \\
\hline & $(0.340)$ & $(0.341)$ & $(0.340)$ & $(0.401)$ & $(0.336)$ & & & & & \\
\hline \multirow[t]{2}{*}{ RD } & & & & & & $-31.92^{* * *}$ & $-32.06^{* * *}$ & $-31.76^{* * *}$ & $-37.81^{* * *}$ & $-24.87^{* * *}$ \\
\hline & & & & & & $(3.035)$ & $(3.045)$ & $(3.024)$ & $(5.155)$ & $(2.777)$ \\
\hline \multirow[t]{2}{*}{ All Credits to GDP Ratio } & $0.301^{* * *}$ & & & & & $0.300^{* * *}$ & & & & \\
\hline & $(0.007)$ & & & & & $(0.007)$ & & & & \\
\hline \multirow[t]{2}{*}{ Short-term Loans to GDP Ratio } & & $0.396^{* * *}$ & & & & & $0.385^{* * *}$ & & & \\
\hline & & $(0.019)$ & & & & & $(0.019)$ & & & \\
\hline \multirow[t]{2}{*}{ Long-term Loans to GDP Ratio } & & & $0.555^{* * *}$ & & & & & $0.558^{* * *}$ & & \\
\hline & & & $(0.011)$ & & & & & $(0.011)$ & & \\
\hline \multirow[t]{2}{*}{ SOE } & & & & $0.267^{* * *}$ & & & & & $0.269^{* * *}$ & \\
\hline & & & & $(0.016)$ & & & & & $(0.016)$ & \\
\hline \multirow[t]{2}{*}{ MNC } & & & & & $0.078^{* * *}$ & & & & & $0.079^{* * *}$ \\
\hline & & & & & $(0.007)$ & & & & & $(0.007)$ \\
\hline Year fixed effect & yes & yes & yes & yes & yes & yes & yes & yes & yes & yes \\
\hline Product-destination fixed effect & yes & yes & yes & yes & yes & yes & yes & yes & yes & yes \\
\hline Observations & $2,809,014$ & $2,809,014$ & $2,809,014$ & 694,968 & 825,963 & $2,809,014$ & $2,809,014$ & $2,809,014$ & 694,968 & 825,963 \\
\hline Adjusted $R^{2}$ & 0.570 & 0.569 & 0.570 & 0.623 & 0.525 & 0.568 & 0.567 & 0.569 & 0.621 & 0.524 \\
\hline
\end{tabular}

Notes: Cluster-robust standard errors in parentheses, clustered by HS-4 product-destination. All regressions include a constant term.

${ }^{* * *}, * *$, and ${ }^{*}$ indicate significance at the $1 \%, 5 \%$, and $10 \%$ level. 
Table 4: Credit Constraints and Export Prices across Product-Destination: Inventory Ratio and Tangibility

\begin{tabular}{|c|c|c|c|c|c|c|c|c|c|c|}
\hline Regressor: & $(1)$ & (2) & (3) & (4) & (5) & (6) & (7) & (8) & (9) & (10) \\
\hline \multirow[t]{2}{*}{$\log (\mathrm{TFP})$} & $0.061^{* * *}$ & $0.059^{* * *}$ & $0.060^{* * *}$ & $0.030^{* * *}$ & $0.078^{* * *}$ & $0.061^{* * *}$ & $0.058^{* * *}$ & $0.059^{* * *}$ & $0.031^{* * *}$ & $0.078^{* * *}$ \\
\hline & $(0.002)$ & $(0.002)$ & $(0.002)$ & $(0.004)$ & $(0.004)$ & $(0.002)$ & $(0.002)$ & $(0.002)$ & $(0.004)$ & $(0.004)$ \\
\hline \multirow[t]{2}{*}{$\log ($ Labor $)$} & $0.026^{* * *}$ & $0.023^{* * *}$ & $0.025^{* * *}$ & $-0.021^{* * *}$ & $0.008^{* *}$ & $0.026^{* * *}$ & $0.023^{* * *}$ & $0.025^{* * *}$ & $-0.021^{* * *}$ & $0.008^{* *}$ \\
\hline & $(0.002)$ & $(0.002)$ & $(0.002)$ & $(0.003)$ & $(0.004)$ & $(0.002)$ & $(0.002)$ & $(0.002)$ & $(0.003)$ & $(0.004)$ \\
\hline \multirow[t]{2}{*}{$\log$ (Capital/Labor) } & $0.043^{* * *}$ & $0.043^{* * *}$ & $0.044^{* * *}$ & $0.019^{* * *}$ & $0.050^{* * *}$ & $0.043^{* * *}$ & $0.043^{* * *}$ & $0.044^{* * *}$ & $0.020^{* * *}$ & $0.050^{* * *}$ \\
\hline & $(0.002)$ & $(0.002)$ & $(0.002)$ & $(0.003)$ & $(0.003)$ & $(0.002)$ & $(0.002)$ & $(0.002)$ & $(0.003)$ & $(0.003)$ \\
\hline \multirow[t]{2}{*}{$\log ($ Wage $)$} & $0.251^{* * *}$ & $0.277^{* * *}$ & $0.245^{* * *}$ & $0.167^{* * *}$ & $0.303^{* * *}$ & $0.253^{* * *}$ & $0.279^{* * *}$ & $0.247^{* * *}$ & $0.169^{* * *}$ & $0.304^{* * *}$ \\
\hline & $(0.005)$ & $(0.005)$ & $(0.005)$ & $(0.006)$ & $(0.008)$ & $(0.005)$ & $(0.005)$ & $(0.005)$ & $(0.006)$ & $(0.008)$ \\
\hline \multirow[t]{2}{*}{ Invent } & $-17.21^{* * *}$ & $-17.33^{* * *}$ & $-17.15^{* * *}$ & $-24.73^{* * *}$ & $-13.07^{* * *}$ & & & & & \\
\hline & $(2.899)$ & $(2.907)$ & $(2.892)$ & $(3.730)$ & $(2.569)$ & & & & & \\
\hline \multirow[t]{2}{*}{ Tang } & & & & & & $1.002^{* * *}$ & $1.039^{* * *}$ & $0.973^{* * *}$ & $1.060^{* * *}$ & $0.900^{* * *}$ \\
\hline & & & & & & $(0.206)$ & $(0.207)$ & $(0.205)$ & $(0.374)$ & $(0.217)$ \\
\hline \multirow[t]{2}{*}{ All Credits to GDP Ratio } & $0.300^{* * *}$ & & & & & $0.300^{* * *}$ & & & & \\
\hline & $(0.007)$ & & & & & $(0.007)$ & & & & \\
\hline \multirow[t]{2}{*}{ Short-term Loans to GDP Ratio } & & $0.387^{* * *}$ & & & & & $0.385^{* * *}$ & & & \\
\hline & & $(0.019)$ & & & & & $(0.019)$ & & & \\
\hline \multirow[t]{2}{*}{ Long-term Loans to GDP Ratio } & & & $0.557^{* * *}$ & & & & & $0.559^{* * *}$ & & \\
\hline & & & $(0.011)$ & & & & & $(0.011)$ & & \\
\hline \multirow[t]{2}{*}{ SOE } & & & & $0.274^{* * *}$ & & & & & $0.275^{* * *}$ & \\
\hline & & & & $(0.016)$ & & & & & $(0.017)$ & \\
\hline \multirow[t]{2}{*}{ MNC } & & & & & $0.077^{* * *}$ & & & & & $0.078^{* * *}$ \\
\hline & & & & & $(0.007)$ & & & & & $(0.007)$ \\
\hline Year fixed effect & yes & yes & yes & yes & yes & yes & yes & yes & yes & yes \\
\hline Product-destination fixed effect & yes & yes & yes & yes & yes & yes & yes & yes & yes & yes \\
\hline Observations & $2,809,014$ & $2,809,014$ & $2,809,014$ & 694,968 & 825,963 & $2,809,014$ & $2,809,014$ & $2,809,014$ & 694,968 & 825,963 \\
\hline Adjusted $R^{2}$ & 0.568 & 0.567 & 0.569 & 0.621 & 0.524 & 0.567 & 0.566 & 0.568 & 0.619 & 0.523 \\
\hline
\end{tabular}

Notes: Cluster-robust standard errors in parentheses, clustered by HS-4 product-destination. All regressions include a constant term.

$* * *, * *$, and ${ }^{*}$ indicate significance at the $1 \%, 5 \%$, and $10 \%$ level. 
Table 5: Credit Constraints and Export Prices across Product: External Finance Dependence and R\&D

\begin{tabular}{|c|c|c|c|c|c|c|c|c|c|c|}
\hline Regressor: & (1) & (2) & (3) & (4) & (5) & (6) & (7) & (8) & (9) & (10) \\
\hline $\log (\mathrm{TFP})$ & $\begin{array}{c}0.055^{* * *} \\
(0.003)\end{array}$ & $\begin{array}{c}0.055^{* * *} \\
(0.003)\end{array}$ & $\begin{array}{c}0.054^{* * *} \\
(0.003)\end{array}$ & $\begin{array}{c}0.028^{* * *} \\
(0.006)\end{array}$ & $\begin{array}{c}0.068^{* * *} \\
(0.005)\end{array}$ & $\begin{array}{c}0.056^{* * *} \\
(0.003)\end{array}$ & $\begin{array}{c}0.055^{* * *} \\
(0.003)\end{array}$ & $\begin{array}{c}0.054^{* * *} \\
(0.003)\end{array}$ & $\begin{array}{c}0.028^{* * *} \\
(0.006)\end{array}$ & $\begin{array}{c}0.069^{* * *} \\
(0.005)\end{array}$ \\
\hline $\log ($ Labor $)$ & $\begin{array}{c}0.034^{* * *} \\
(0.003)\end{array}$ & $\begin{array}{c}0.031^{* * *} \\
(0.003)\end{array}$ & $\begin{array}{c}0.033^{* * *} \\
(0.003)\end{array}$ & $\begin{array}{l}-0.003 \\
(0.004)\end{array}$ & $\begin{array}{c}0.036^{* * *} \\
(0.005)\end{array}$ & $\begin{array}{c}0.034^{* * *} \\
(0.003)\end{array}$ & $\begin{array}{c}0.032^{* * *} \\
(0.003)\end{array}$ & $\begin{array}{c}0.033^{* * *} \\
(0.003)\end{array}$ & $\begin{array}{l}-0.003 \\
(0.004)\end{array}$ & $\begin{array}{c}0.036^{* * *} \\
(0.005)\end{array}$ \\
\hline $\log$ (Capitla/Labor) & $\begin{array}{c}0.039^{* * *} \\
(0.002)\end{array}$ & $\begin{array}{c}0.039^{* * *} \\
(0.002)\end{array}$ & $\begin{array}{c}0.040^{* * *} \\
(0.002)\end{array}$ & $\begin{array}{l}0.010^{* *} \\
(0.004)\end{array}$ & $\begin{array}{c}0.048^{* * *} \\
(0.004)\end{array}$ & $\begin{array}{c}0.038^{* * *} \\
(0.002)\end{array}$ & $\begin{array}{c}0.038^{* * *} \\
(0.002)\end{array}$ & $\begin{array}{c}0.040^{* * *} \\
(0.002)\end{array}$ & $\begin{array}{l}0.010^{* *} \\
(0.004)\end{array}$ & $\begin{array}{c}0.047^{* * *} \\
(0.004)\end{array}$ \\
\hline $\log$ (Wage) & $\begin{array}{c}0.219^{* * *} \\
(0.006)\end{array}$ & $\begin{array}{c}0.242^{* * *} \\
(0.006)\end{array}$ & $\begin{array}{c}0.214^{* * *} \\
(0.006)\end{array}$ & $\begin{array}{c}0.134^{* * *} \\
(0.010)\end{array}$ & $\begin{array}{c}0.264^{* * *} \\
(0.010)\end{array}$ & $\begin{array}{c}0.218^{* * *} \\
(0.006)\end{array}$ & $\begin{array}{c}0.242^{* * *} \\
(0.006)\end{array}$ & $\begin{array}{c}0.214^{* * *} \\
(0.006)\end{array}$ & $\begin{array}{c}0.134^{* * *} \\
(0.010)\end{array}$ & $\begin{array}{c}0.264^{* * *} \\
(0.010)\end{array}$ \\
\hline extfin & $\begin{array}{c}-2.478^{* * *} \\
(0.380)\end{array}$ & $\begin{array}{c}-2.490^{* * *} \\
(0.381)\end{array}$ & $\begin{array}{c}-2.467^{* * *} \\
(0.380)\end{array}$ & $\begin{array}{c}-2.792^{* * *} \\
(0.440)\end{array}$ & $\begin{array}{c}-2.168^{* * *} \\
(0.440)\end{array}$ & & & & & \\
\hline $\mathrm{RD}$ & & & & & & $\begin{array}{c}-20.25^{* * *} \\
(2.505)\end{array}$ & $\begin{array}{c}-20.36^{* * *} \\
(2.517)\end{array}$ & $\begin{array}{c}-20.17^{* * *} \\
(2.499)\end{array}$ & $\begin{array}{c}-24.46^{* * *} \\
(4.578)\end{array}$ & $\begin{array}{c}-15.97^{* * * *} \\
(4.177)\end{array}$ \\
\hline All Credits to GDP Ratio & $\begin{array}{c}0.288^{* * *} \\
(0.009)\end{array}$ & & & & & $\begin{array}{c}0.288^{* * *} \\
(0.009)\end{array}$ & & & & \\
\hline Short-term Loans to GDP Ratio & & $\begin{array}{c}0.452^{* * *} \\
(0.027)\end{array}$ & & & & & $\begin{array}{c}0.450^{* * *} \\
(0.027)\end{array}$ & & & \\
\hline Long-term Loans to GDP Ratio & & & $\begin{array}{c}0.517^{* * *} \\
(0.014)\end{array}$ & & & & & $\begin{array}{c}0.518^{* * *} \\
(0.014)\end{array}$ & & \\
\hline SOE & & & & $\begin{array}{c}0.177^{* * *} \\
(0.020)\end{array}$ & & & & & $\begin{array}{c}0.176^{* * *} \\
(0.020)\end{array}$ & \\
\hline MNC & & & & & $\begin{array}{c}0.074^{* * *} \\
(0.010) \\
\end{array}$ & & & & & $\begin{array}{c}0.074^{* * *} \\
(0.010)\end{array}$ \\
\hline Year fixed effect & yes & yes & yes & yes & yes & yes & yes & yes & yes & yes \\
\hline Product fixed effect & yes & yes & yes & yes & yes & yes & yes & yes & yes & yes \\
\hline constant & yes & yes & yes & yes & yes & yes & yes & yes & yes & yes \\
\hline Observations & 1045764 & 1045764 & 1045764 & 225640 & 355866 & 1045764 & 1045764 & 1045764 & 225640 & 355866 \\
\hline Adjusted $R^{2}$ & 0.522 & 0.521 & 0.522 & 0.596 & 0.481 & 0.521 & 0.520 & 0.522 & 0.596 & 0.481 \\
\hline
\end{tabular}

Notes: Cluster-robust standard errors in parentheses, clustered by HS-4 product. All regressions include a constant term.

$* * *, * *$, and ${ }^{*}$ indicate significance at the $1 \%, 5 \%$, and $10 \%$ level. 
Table 6: Credit Constraints and Export Prices across Product: Inventory Ratio and Tangibility

\begin{tabular}{|c|c|c|c|c|c|c|c|c|c|c|}
\hline Regressor: & (1) & (2) & (3) & (4) & (5) & (6) & (7) & (8) & (9) & (10) \\
\hline \multirow[t]{2}{*}{$\log (\mathrm{TFP})$} & $0.056^{* * *}$ & $0.055^{* * *}$ & $0.055^{* * *}$ & $0.028^{* * *}$ & $0.069^{* * *}$ & $0.056^{* * *}$ & $0.055^{* * *}$ & $0.055^{* * *}$ & $0.028^{* * *}$ & $0.069^{* * *}$ \\
\hline & $(0.003)$ & $(0.003)$ & $(0.003)$ & $(0.006)$ & $(0.005)$ & $(0.003)$ & $(0.003)$ & $(0.003)$ & $(0.006)$ & $(0.005)$ \\
\hline \multirow[t]{2}{*}{$\log$ (Labor) } & $0.034^{* * *}$ & $0.031^{* * *}$ & $0.033^{* * *}$ & -0.003 & $0.036^{* * *}$ & $0.034^{* * *}$ & $0.031^{* * *}$ & $0.033^{* * *}$ & -0.003 & $0.036^{* * *}$ \\
\hline & $(0.003)$ & $(0.003)$ & $(0.003)$ & $(0.004)$ & $(0.005)$ & $(0.003)$ & $(0.003)$ & $(0.003)$ & $(0.004)$ & $(0.005)$ \\
\hline \multirow[t]{2}{*}{$\log$ (Capitla/Labor) } & $0.038^{* * *}$ & $0.038^{* * *}$ & $0.040^{* * *}$ & $0.010^{* *}$ & $0.047^{* * *}$ & $0.038^{* * *}$ & $0.038^{* * *}$ & $0.040^{* * *}$ & $0.010^{* *}$ & $0.047^{* * *}$ \\
\hline & $(0.002)$ & $(0.002)$ & $(0.002)$ & $(0.004)$ & $(0.004)$ & $(0.002)$ & $(0.002)$ & $(0.002)$ & $(0.004)$ & $(0.004)$ \\
\hline \multirow[t]{2}{*}{ log(Wage) } & $0.218^{* * *}$ & $0.242^{* * *}$ & $0.214^{* * *}$ & $0.134^{* * *}$ & $0.263^{* * *}$ & $0.219^{* * *}$ & $0.242^{* * *}$ & $0.214^{* * *}$ & $0.134^{* * *}$ & $0.263^{* * *}$ \\
\hline & $(0.006)$ & $(0.006)$ & $(0.006)$ & $(0.010)$ & $(0.010)$ & $(0.006)$ & $(0.006)$ & $(0.006)$ & $(0.010)$ & $(0.010)$ \\
\hline \multirow[t]{2}{*}{ Invent } & $-8.184^{* * *}$ & $-8.192^{* * *}$ & $-8.175^{* * *}$ & $-10.03^{* * *}$ & $-7.386^{* * *}$ & & & & & \\
\hline & $(2.674)$ & (2.677) & $(2.669)$ & $(3.231)$ & $(2.752)$ & & & & & \\
\hline \multirow[t]{2}{*}{ Tang } & & & & & & 0.117 & 0.119 & 0.114 & 0.0697 & 0.123 \\
\hline & & & & & & $(0.175)$ & $(0.177)$ & $(0.174)$ & $(0.276)$ & $(0.298)$ \\
\hline \multirow[t]{2}{*}{ All Credits to GDP Ratio } & $0.289^{* * *}$ & & & & & $0.289^{* * *}$ & & & & \\
\hline & $(0.009)$ & & & & & $(0.009)$ & & & & \\
\hline \multirow[t]{2}{*}{ Short-term Loans to GDP Ratio } & & $0.450^{* * *}$ & & & & & $0.450^{* * *}$ & & & \\
\hline & & $(0.027)$ & & & & & $(0.027)$ & & & \\
\hline \multirow[t]{2}{*}{ Long-term Loans to GDP Ratio } & & & $0.518^{* * *}$ & & & & & $0.518^{* * *}$ & & \\
\hline & & & $(0.015)$ & & & & & $(0.015)$ & & \\
\hline \multirow[t]{2}{*}{ SOE } & & & & $0.177^{* * *}$ & & & & & $0.177^{* * *}$ & \\
\hline & & & & $(0.020)$ & & & & & $(0.020)$ & \\
\hline \multirow[t]{2}{*}{ MNC } & & & & & $0.073^{* * *}$ & & & & & $0.073^{* * *}$ \\
\hline & & & & & $(0.010)$ & & & & & $(0.010)$ \\
\hline Year fixed effect & yes & yes & yes & yes & yes & yes & yes & yes & yes & yes \\
\hline Product fixed effect & yes & yes & yes & yes & yes & yes & yes & yes & yes & yes \\
\hline constant & yes & yes & yes & yes & yes & yes & yes & yes & yes & yes \\
\hline Observations & 1045764 & 1045764 & 1045764 & 225640 & 355866 & 1045764 & 1045764 & 1045764 & 225640 & 355866 \\
\hline Adjusted $R^{2}$ & 0.521 & 0.52 & 0.522 & 0.595 & 0.481 & 0.521 & 0.520 & 0.521 & 0.595 & 0.481 \\
\hline
\end{tabular}

Notes: Cluster-robust standard errors in parentheses, clustered by HS-4 product. All regressions include a constant term.

${ }^{* * *}, * *$, and ${ }^{*}$ indicate significance at the $1 \%, 5 \%$, and $10 \%$ level. 
Table 7: Credit Constraints and Export Prices: External Finance Dependence based on Chinese Data

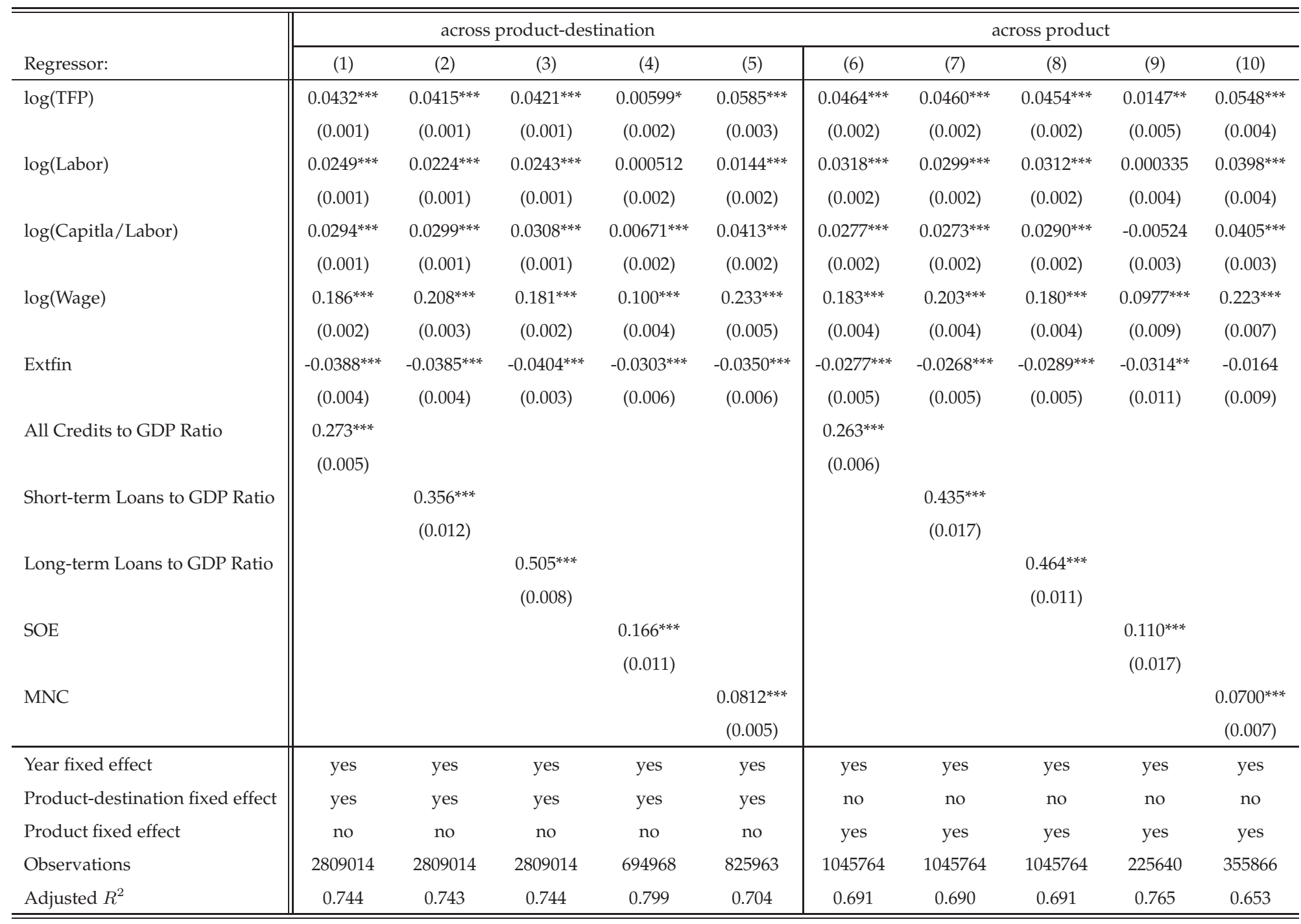

Notes: Cluster-robust standard errors in parentheses, clustered by HS-8 product-country in specifications (1)-(5) and by HS-8 product in (6)-(10).

All regressions include a constant term. ${ }^{* * *},{ }^{* *}$, and ${ }^{*}$ indicate significance at the $1 \%, 5 \%$, and $10 \%$ level. 
Table 8: Export Prices across Product and Destination: Quality and Net-Quality Price $(\sigma=12)$

\begin{tabular}{|c|c|c|c|c|c|c|c|c|c|c|}
\hline \multirow[b]{2}{*}{ Regressor: } & \multicolumn{5}{|c|}{ Dependent Variable: Quality } & \multicolumn{5}{|c|}{ Dependent Variable: Net-Quality Price } \\
\hline & (1) & (2) & (3) & (4) & (5) & (6) & (7) & (8) & (9) & (10) \\
\hline \multirow[t]{2}{*}{$\log (\mathrm{TFP})$} & $0.064^{* * *}$ & $0.062^{* * *}$ & $0.062^{* * *}$ & $0.033^{* * *}$ & $0.080^{* * *}$ & $-0.004^{* * *}$ & $-0.004^{* * *}$ & $-0.004^{* * *}$ & $-0.005^{* * *}$ & $-0.003^{* * *}$ \\
\hline & $(0.002)$ & $(0.002)$ & $(0.002)$ & $(0.004)$ & $(0.004)$ & $(0.000)$ & $(0.000)$ & $(0.000)$ & $(0.000)$ & $(0.001)$ \\
\hline \multirow[t]{2}{*}{$\log ($ Labor $)$} & $0.026^{* * *}$ & $0.024^{* * *}$ & $0.025^{* * *}$ & $-0.012^{* * *}$ & -0.002 & -0.000 & $-0.001^{*}$ & 0.000 & $-0.008^{* * *}$ & $0.009^{* * *}$ \\
\hline & $(0.002)$ & $(0.002)$ & $(0.002)$ & $(0.003)$ & $(0.004)$ & $(0.000)$ & $(0.000)$ & $(0.000)$ & $(0.000)$ & $(0.001)$ \\
\hline \multirow[t]{2}{*}{$\log ($ Capitla/Labor) } & $0.044^{* * *}$ & $0.045^{* * *}$ & $0.046^{* * *}$ & $0.021^{* * *}$ & $0.051^{* * *}$ & $-0.001^{* * *}$ & $-0.001^{* *}$ & $-0.001^{* * *}$ & $-0.001^{* * *}$ & -0.000 \\
\hline & $(0.002)$ & $(0.002)$ & $(0.002)$ & $(0.003)$ & $(0.003)$ & $(0.000)$ & $(0.000)$ & $(0.000)$ & $(0.000)$ & $(0.000)$ \\
\hline \multirow[t]{2}{*}{$\log ($ Wage $)$} & $0.241^{* * *}$ & $0.265^{* * *}$ & $0.236^{* * *}$ & $0.162^{* * *}$ & $0.294^{* * *}$ & $0.010^{* * *}$ & $0.012^{* * *}$ & $0.009^{* * *}$ & $0.005^{* * *}$ & $0.011^{* * *}$ \\
\hline & $(0.005)$ & $(0.005)$ & $(0.005)$ & $(0.006)$ & $(0.008)$ & $(0.000)$ & $(0.000)$ & $(0.000)$ & $(0.001)$ & $(0.001)$ \\
\hline \multirow[t]{2}{*}{ ExtFin } & $-3.501^{* * *}$ & $-3.522^{* * *}$ & $-3.481^{* * *}$ & $-4.028^{* * *}$ & $-3.063^{* * *}$ & $0.036^{* *}$ & $0.038^{* *}$ & $0.037^{* *}$ & $0.033^{* *}$ & $0.103^{* * *}$ \\
\hline & $(0.339)$ & $(0.340)$ & $(0.339)$ & $(0.406)$ & $(0.333)$ & $(0.016)$ & $(0.015)$ & $(0.015)$ & $(0.015)$ & $(0.019)$ \\
\hline \multirow[t]{2}{*}{ All Credits to GDP Ratio } & $0.300^{* * *}$ & & & & & 0.000 & & & & \\
\hline & $(0.007)$ & & & & & $(0.001)$ & & & & \\
\hline \multirow[t]{2}{*}{ Short-term Loans to GDP Ratio } & & $0.445^{* * *}$ & & & & & $-0.049^{* * *}$ & & & \\
\hline & & $(0.019)$ & & & & & $(0.003)$ & & & \\
\hline \multirow[t]{2}{*}{ Long-term Loans to GDP Ratio } & & & $0.538^{* * *}$ & & & & & $0.018^{* * *}$ & & \\
\hline & & & $(0.011)$ & & & & & $(0.002)$ & & \\
\hline \multirow[t]{2}{*}{$\mathrm{SOE}$} & & & & $0.245^{* * *}$ & & & & & $0.021^{* * *}$ & \\
\hline & & & & $(0.016)$ & & & & & $(0.002)$ & \\
\hline \multirow[t]{2}{*}{ MNC } & & & & & $0.049^{* * *}$ & & & & & $0.029^{* * *}$ \\
\hline & & & & & $(0.007)$ & & & & & $(0.001)$ \\
\hline Year fixed effect & yes & yes & yes & yes & yes & yes & yes & yes & yes & yes \\
\hline Product-destination fixed effect & yes & yes & yes & yes & yes & yes & yes & yes & yes & yes \\
\hline Observations & 2809014 & 2809014 & 2809014 & 694968 & 825963 & 2809014 & 2809014 & 2809014 & 694968 & 825963 \\
\hline Adjusted $R^{2}$ & 0.088 & 0.086 & 0.088 & 0.124 & 0.112 & 0.982 & 0.982 & 0.982 & 0.987 & 0.978 \\
\hline
\end{tabular}

Notes: Cluster-robust standard errors in parentheses, clustered by HS-4 product-destination. All regressions include a constant term.

${ }^{* * *}, * *$, and ${ }^{*}$ indicate significance at the $1 \%, 5 \%$, and $10 \%$ level. Using ExtFin computed by Chinese data does not alter the results in this table. 
Table 9: Export Prices across Product and Destination: Quality and Net-Quality Price $(\sigma=6)$

\begin{tabular}{|c|c|c|c|c|c|c|c|c|c|c|}
\hline \multirow[b]{2}{*}{ Regressor: } & \multicolumn{5}{|c|}{ Dependent Variable: Quality } & \multicolumn{5}{|c|}{ Dependent Variable: Net-Quality Price } \\
\hline & (1) & (2) & (3) & (4) & (5) & (6) & (7) & (8) & (9) & $(10)$ \\
\hline \multirow[t]{2}{*}{$\log (\mathrm{TFP})$} & $0.068^{* * *}$ & $0.068^{* * *}$ & $0.067^{* * *}$ & $0.039^{* * *}$ & $0.083^{* * *}$ & $-0.009^{* * *}$ & $-0.010^{* * *}$ & $-0.008^{* * *}$ & $-0.011^{* * *}$ & $-0.007^{* * *}$ \\
\hline & $(0.002)$ & $(0.002)$ & $(0.002)$ & $(0.004)$ & $(0.004)$ & $(0.001)$ & $(0.001)$ & $(0.001)$ & $(0.001)$ & $(0.001)$ \\
\hline \multirow[t]{2}{*}{$\log ($ Labor $)$} & $0.027^{* * *}$ & $0.025^{* * *}$ & $0.025^{* * *}$ & -0.001 & $-0.013^{* * *}$ & -0.000 & $-0.002^{* *}$ & -0.000 & $-0.019^{* * *}$ & $0.020^{* * *}$ \\
\hline & $(0.002)$ & $(0.002)$ & $(0.002)$ & $(0.003)$ & $(0.004)$ & $(0.001)$ & $(0.001)$ & $(0.001)$ & $(0.001)$ & $(0.001)$ \\
\hline \multirow[t]{2}{*}{$\log$ (Capitla/Labor) } & $0.046^{* * *}$ & $0.046^{* * *}$ & $0.047^{* * *}$ & $0.023^{* * *}$ & $0.052^{* * *}$ & $-0.003^{* * *}$ & $-0.002^{* * *}$ & $-0.003^{* * *}$ & $-0.002^{* * *}$ & -0.001 \\
\hline & $(0.002)$ & $(0.002)$ & $(0.002)$ & $(0.003)$ & $(0.003)$ & $(0.001)$ & $(0.001)$ & $(0.001)$ & $(0.001)$ & $(0.001)$ \\
\hline \multirow[t]{2}{*}{$\log ($ Wage $)$} & $0.229^{* * *}$ & $0.251^{* * *}$ & $0.226^{* * *}$ & $0.156^{* * *}$ & $0.280^{* * *}$ & $0.022^{* * *}$ & $0.026^{* * *}$ & $0.019^{* * *}$ & $0.010^{* * *}$ & $0.024^{* * *}$ \\
\hline & $(0.005)$ & $(0.005)$ & $(0.005)$ & $(0.006)$ & $(0.008)$ & $(0.001)$ & $(0.001)$ & $(0.001)$ & $(0.002)$ & $(0.002)$ \\
\hline \multirow[t]{2}{*}{ Extfin } & $-3.550^{* * *}$ & $-3.574^{* * *}$ & $-3.531^{* * *}$ & $-4.071^{* * *}$ & $-3.190^{* * *}$ & $0.085^{* *}$ & $0.090^{* * *}$ & $0.086^{* *}$ & $0.076^{* *}$ & $0.230^{* * *}$ \\
\hline & $(0.339)$ & $(0.339)$ & $(0.339)$ & $(0.412)$ & $(0.332)$ & $(0.034)$ & $(0.034)$ & $(0.034)$ & $(0.033)$ & $(0.043)$ \\
\hline \multirow[t]{2}{*}{ All Credits to GDP Ratio } & $0.300^{* * *}$ & & & & & 0.000 & & & & \\
\hline & $(0.007)$ & & & & & $(0.003)$ & & & & \\
\hline \multirow[t]{2}{*}{ Short-term Loans to GDP Ratio } & & $0.504^{* * *}$ & & & & & $-0.108^{* * *}$ & & & \\
\hline & & $(0.019)$ & & & & & $(0.007)$ & & & \\
\hline \multirow[t]{2}{*}{ Long-term Loans to GDP Ratio } & & & $0.518^{* * *}$ & & & & & $0.038^{* * *}$ & & \\
\hline & & & $(0.012)$ & & & & & $(0.005)$ & & \\
\hline \multirow[t]{2}{*}{ SOE } & & & & $0.221^{* * *}$ & & & & & $0.046^{* * *}$ & \\
\hline & & & & $(0.016)$ & & & & & $(0.004)$ & \\
\hline \multirow[t]{2}{*}{ MNC } & & & & & $0.014^{* *}$ & & & & & $0.064^{* * *}$ \\
\hline & & & & & $(0.007)$ & & & & & $(0.002)$ \\
\hline Year fixed effect & yes & yes & yes & yes & yes & yes & yes & yes & yes & yes \\
\hline Product-destination fixed effect & yes & yes & yes & yes & yes & yes & yes & yes & yes & yes \\
\hline constant & yes & yes & yes & yes & yes & yes & yes & yes & yes & yes \\
\hline Observations & 2809014 & 2809014 & 2809014 & 694968 & 825963 & 2809014 & 2809014 & 2809014 & 694968 & 825963 \\
\hline Adjusted $R^{2}$ & 0.082 & 0.080 & 0.082 & 0.118 & 0.103 & 0.921 & 0.922 & 0.922 & 0.941 & 0.903 \\
\hline
\end{tabular}

Notes: Cluster-robust standard errors in parentheses, clustered by HS-4 product-destination. All regressions include a constant term.

${ }^{* * *}, * *$, and * indicate significance at the 1\%, 5\%, and 10\% level. Using ExtFin computed by Chinese data does not alter the results in this table. 
Table 10: Credit Constraints and Export Prices (with and without Controlling for Wage)

\begin{tabular}{|c|c|c|c|c|c|c|c|c|c|c|}
\hline Regressor: & (1) & (2) & (3) & (4) & (5) & (6) & (7) & (8) & (9) & (10) \\
\hline $\log (\mathrm{TFP})$ & $\begin{array}{l}0.105^{* * *} \\
(0.003)\end{array}$ & $\begin{array}{c}0.109^{* * *} \\
(0.003)\end{array}$ & $\begin{array}{c}0.102^{* * *} \\
(0.003)\end{array}$ & $\begin{array}{c}0.052^{* * *} \\
(0.004)\end{array}$ & $\begin{array}{c}0.139^{* * *} \\
(0.004)\end{array}$ & $\begin{array}{c}0.060^{* * *} \\
(0.002)\end{array}$ & $\begin{array}{c}0.058^{* * *} \\
(0.002)\end{array}$ & $\begin{array}{c}0.059^{* * *} \\
(0.002)\end{array}$ & $\begin{array}{c}0.029^{* * *} \\
(0.004)\end{array}$ & $\begin{array}{c}0.077^{* * *} \\
(0.004)\end{array}$ \\
\hline $\log ($ Labor $)$ & $\begin{array}{c}0.018^{* * *} \\
(0.002)\end{array}$ & $\begin{array}{c}0.014^{* * *} \\
(0.002)\end{array}$ & $\begin{array}{c}0.017^{* * *} \\
(0.002)\end{array}$ & $\begin{array}{c}-0.026^{* * *} \\
(0.003)\end{array}$ & $\begin{array}{l}-0.005 \\
(0.004)\end{array}$ & $\begin{array}{c}0.026^{* * *} \\
(0.002)\end{array}$ & $\begin{array}{c}0.0235^{* * *} \\
(0.002)\end{array}$ & $\begin{array}{c}0.025^{* * *} \\
(0.002)\end{array}$ & $\begin{array}{c}-0.020^{* * *} \\
(0.003)\end{array}$ & $\begin{array}{l}0.008^{* *} \\
(0.004)\end{array}$ \\
\hline $\log ($ Capitla/Labor $)$ & $\begin{array}{c}0.073^{* * *} \\
(0.002)\end{array}$ & $\begin{array}{c}0.077^{* * *} \\
(0.002)\end{array}$ & $\begin{array}{c}0.074^{* * *} \\
(0.002)\end{array}$ & $\begin{array}{c}0.032^{* * *} \\
(0.003)\end{array}$ & $\begin{array}{c}0.098^{* * *} \\
(0.003)\end{array}$ & $\begin{array}{l}0.043^{* * *} \\
(0.002)\end{array}$ & $\begin{array}{c}0.044^{* * *} \\
(0.002)\end{array}$ & $\begin{array}{c}0.045^{* * *} \\
(0.002)\end{array}$ & $\begin{array}{c}0.020^{* * *} \\
(0.003)\end{array}$ & $\begin{array}{c}0.051^{* * *} \\
(0.003)\end{array}$ \\
\hline $\log ($ Wage $)$ & & & & & & $\begin{array}{c}0.251^{* * *} \\
(0.005)\end{array}$ & $\begin{array}{c}0.277^{* * *} \\
(0.005)\end{array}$ & $\begin{array}{c}0.245^{* * *} \\
(0.005)\end{array}$ & $\begin{array}{c}0.167^{* * *} \\
(0.006)\end{array}$ & $\begin{array}{c}0.305^{* * *} \\
(0.008)\end{array}$ \\
\hline ExtFin & $\begin{array}{c}-3.505^{* * *} \\
(0.343)\end{array}$ & $\begin{array}{c}-3.538^{* * *} \\
(0.344)\end{array}$ & $\begin{array}{c}-3.478^{* * *} \\
(0.343)\end{array}$ & $\begin{array}{c}-4.009^{* * *} \\
(0.406)\end{array}$ & $\begin{array}{c}-2.976^{* * *} \\
(0.338)\end{array}$ & $\begin{array}{c}-3.465^{* * *} \\
(0.340)\end{array}$ & $\begin{array}{c}-3.484^{* * *} \\
(0.341)\end{array}$ & $\begin{array}{c}-3.445^{* * *} \\
(0.340)\end{array}$ & $\begin{array}{c}-3.995^{* * *} \\
(0.401)\end{array}$ & $\begin{array}{c}-2.959^{* * *} \\
(0.336)\end{array}$ \\
\hline All Credits to GDP Ratio & $\begin{array}{c}0.395^{* * *} \\
(0.007)\end{array}$ & & & & & $\begin{array}{c}0.301^{* * *} \\
(0.007)\end{array}$ & & & & \\
\hline Short-term Loans to GDP Ratio & & $\begin{array}{c}0.576^{* * *} \\
(0.019)\end{array}$ & & & & & $\begin{array}{l}0.396^{* * *} \\
(0.019)\end{array}$ & & & \\
\hline Long-term Loans to GDP Ratio & & & $\begin{array}{l}0.713^{* * *} \\
(0.011)\end{array}$ & & & & & $\begin{array}{c}0.555^{* * *} \\
(0.011)\end{array}$ & & \\
\hline SOE & & & & $\begin{array}{c}0.304^{* * *} \\
(0.016)\end{array}$ & & & & & $\begin{array}{c}0.267^{* * *} \\
(0.016)\end{array}$ & \\
\hline MNC & & & & & $\begin{array}{c}0.089^{* * *} \\
(0.007)\end{array}$ & & & & & $\begin{array}{c}0.078^{* * *} \\
(0.007)\end{array}$ \\
\hline Year fixed effect & yes & yes & yes & yes & yes & yes & yes & yes & yes & yes \\
\hline Product-destination fixed effect & yes & yes & yes & yes & yes & yes & yes & yes & yes & yes \\
\hline Observations & 2809014 & 2809014 & 2809014 & 694968 & 825963 & 2809014 & 2809014 & 2809014 & 694968 & 825963 \\
\hline Adjusted $R^{2}$ & 0.567 & 0.565 & 0.567 & 0.622 & 0.519 & 0.570 & 0.569 & 0.570 & 0.623 & 0.525 \\
\hline
\end{tabular}

Notes: Cluster-robust standard errors in parentheses, clustered by HS-4 product-destination. All regressions include a constant term.

${ }^{* * *},{ }^{* *}$, and ${ }^{*}$ indicate significance at the $1 \%, 5 \%$, and $10 \%$ level. Using ExtFin computed by Chinese data does not alter the results in this table. 
Table 11: Credit Constraints and Export Prices: Effects of Quality Variation

\begin{tabular}{|c|c|c|c|c|c|c|c|c|c|c|}
\hline Regressor: & (1) & (2) & (3) & (4) & (5) & (6) & (7) & (8) & (9) & (10) \\
\hline $\log ($ TFP) & $\begin{array}{c}0.059^{* * * *} \\
(0.002)\end{array}$ & $\begin{array}{c}0.058^{* * *} \\
(0.002)\end{array}$ & $\begin{array}{c}0.058^{* * *} \\
(0.002)\end{array}$ & $\begin{array}{c}0.028^{* * * *} \\
(0.004)\end{array}$ & $\begin{array}{c}0.077^{* * *} \\
(0.004)\end{array}$ & $\begin{array}{c}0.060^{* * *} \\
(0.002)\end{array}$ & $\begin{array}{c}0.058^{* * * *} \\
(0.002)\end{array}$ & $\begin{array}{c}0.058^{* * * *} \\
(0.002)\end{array}$ & $\begin{array}{c}0.017^{* * *} \\
(0.003)\end{array}$ & $\begin{array}{c}0.079^{* * * *} \\
(0.004)\end{array}$ \\
\hline $\log ($ Labor $)$ & $\begin{array}{c}0.026^{* * *} \\
(0.002)\end{array}$ & $\begin{array}{c}0.024^{* * *} \\
(0.002)\end{array}$ & $\begin{array}{c}0.025^{* * *} \\
(0.002)\end{array}$ & $\begin{array}{c}-0.020^{* * *} \\
(0.003)\end{array}$ & $\begin{array}{l}0.008^{* *} \\
(0.004)\end{array}$ & $\begin{array}{c}0.031^{* * *} \\
(0.002)\end{array}$ & $\begin{array}{c}0.029^{* * *} \\
(0.002)\end{array}$ & $\begin{array}{c}0.030^{* * *} \\
(0.002)\end{array}$ & $\begin{array}{c}-0.008^{* * *} \\
(0.003)\end{array}$ & $\begin{array}{c}0.010^{* * *} \\
(0.004)\end{array}$ \\
\hline $\log$ (Capital/Labor) & $\begin{array}{c}0.043^{* * * *} \\
(0.002)\end{array}$ & $\begin{array}{c}0.044^{* * *} \\
(0.002)\end{array}$ & $\begin{array}{c}0.045^{* * *} \\
(0.002)\end{array}$ & $\begin{array}{c}0.020^{* * *} \\
(0.003)\end{array}$ & $\begin{array}{c}0.051^{* * *} \\
(0.003)\end{array}$ & $\begin{array}{c}0.046^{* * *} \\
(0.002)\end{array}$ & $\begin{array}{c}0.046^{* * * *} \\
(0.002)\end{array}$ & $\begin{array}{c}0.047^{* * *} \\
(0.002)\end{array}$ & $\begin{array}{c}0.026^{* * *} \\
(0.003)\end{array}$ & $\begin{array}{c}0.050^{* * *} \\
(0.003)\end{array}$ \\
\hline $\log ($ Wage $)$ & $\begin{array}{c}0.251^{* * *} \\
(0.005)\end{array}$ & $\begin{array}{c}0.277^{* * *} \\
(0.005)\end{array}$ & $\begin{array}{c}0.245^{* * *} \\
(0.005)\end{array}$ & $\begin{array}{c}0.158^{* * * *} \\
(0.006)\end{array}$ & $\begin{array}{c}0.304^{* * *} \\
(0.008)\end{array}$ & $\begin{array}{c}0.231^{* * *} \\
(0.005)\end{array}$ & $\begin{array}{c}0.256^{* * *} \\
(0.005)\end{array}$ & $\begin{array}{c}0.225^{* * *} \\
(0.005)\end{array}$ & $\begin{array}{c}0.140^{* * *} \\
(0.006)\end{array}$ & $\begin{array}{c}0.287^{* * *} \\
(0.007)\end{array}$ \\
\hline ExtFin & $\begin{array}{c}-3.130^{* * *} \\
(0.319)\end{array}$ & $\begin{array}{c}-3.153^{* * *} \\
(0.320)\end{array}$ & $\begin{array}{c}-3.111^{* * *} \\
(0.319)\end{array}$ & $\begin{array}{c}-3.608^{* * *} \\
(0.373)\end{array}$ & $\begin{array}{c}-2.639^{* * *} \\
(0.314)\end{array}$ & $\begin{array}{c}-1.764^{* * *} \\
(0.236)\end{array}$ & $\begin{array}{c}-1.786^{* * *} \\
(0.237)\end{array}$ & $\begin{array}{c}-1.748^{* * *} \\
(0.237)\end{array}$ & $\begin{array}{c}-1.529^{* * *} \\
(0.237)\end{array}$ & $\begin{array}{c}-1.821^{* * *} \\
(0.271)\end{array}$ \\
\hline ExtFin $\times$ Dummy & $\begin{array}{c}-0.521^{* * *} \\
(0.054)\end{array}$ & $\begin{array}{c}-0.521^{* * *} \\
(0.054)\end{array}$ & $\begin{array}{c}-0.520^{* * *} \\
(0.054)\end{array}$ & $\begin{array}{c}-0.512^{* * *} \\
(0.070)\end{array}$ & $\begin{array}{c}-0.503^{* * *} \\
(0.065)\end{array}$ & $\begin{array}{c}-0.240^{* * *} \\
(0.045)\end{array}$ & $\begin{array}{c}-0.240^{* * *} \\
(0.045)\end{array}$ & $\begin{array}{c}-0.240^{* * *} \\
(0.045)\end{array}$ & $\begin{array}{c}-0.101^{* *} \\
(0.051)\end{array}$ & $\begin{array}{c}-0.346^{* * *} \\
(0.058)\end{array}$ \\
\hline Dummy & $\begin{array}{c}-0.215^{* * *} \\
(0.018)\end{array}$ & $\begin{array}{l}-0.032 \\
(0.022)\end{array}$ & $\begin{array}{c}-0.184^{* * *} \\
(0.013)\end{array}$ & $\begin{array}{c}-0.078^{* * *} \\
(0.013)\end{array}$ & $\begin{array}{l}-0.005 \\
(0.014)\end{array}$ & $\begin{array}{c}-0.182^{* * *} \\
(0.016)\end{array}$ & $\begin{array}{l}-0.011 \\
(0.022)\end{array}$ & $\begin{array}{c}-0.149^{* * *} \\
(0.012)\end{array}$ & $\begin{array}{c}-0.047^{* * *} \\
(0.011)\end{array}$ & $\begin{array}{c}0.007 \\
(0.013)\end{array}$ \\
\hline All Credits to GDP Ratio & $\begin{array}{c}0.200^{* * *} \\
(0.009)\end{array}$ & & & & & $\begin{array}{c}0.218^{* * *} \\
(0.009)\end{array}$ & & & & \\
\hline All Credits to GDP Ratio $\times$ Dummy & $\begin{array}{c}0.183^{* * * *} \\
(0.014)\end{array}$ & & & & & $\begin{array}{c}0.175^{* * *} \\
(0.013)\end{array}$ & & & & \\
\hline Short-term Loans to GDP Ratio & & $\begin{array}{c}0.375^{* * *} \\
(0.024)\end{array}$ & & & & & $\begin{array}{c}0.406^{* * * *} \\
(0.024)\end{array}$ & & & \\
\hline Short-term Loans to GDP Ratio $\times$ Dummy & & $\begin{array}{c}0.038 \\
(0.035)\end{array}$ & & & & & $\begin{array}{c}0.045 \\
(0.035)\end{array}$ & & & \\
\hline Long-term Loans to GDP Ratio & & & $\begin{array}{c}0.333^{* * *} \\
(0.015)\end{array}$ & & & & & $\begin{array}{c}0.364^{* * *} \\
(0.015)\end{array}$ & & \\
\hline Short-term Loans to GDP Ratio $\times$ Dummy & & & $\begin{array}{c}0.395^{* * *} \\
(0.023)\end{array}$ & & & & & $\begin{array}{c}0.372^{* * *} \\
(0.022)\end{array}$ & & \\
\hline SOE & & & & $\begin{array}{c}0.003 \\
(0.011)\end{array}$ & & & & & $\begin{array}{c}-0.025^{* *} \\
(0.011)\end{array}$ & \\
\hline SOE $\times$ Dummy & & & & $\begin{array}{c}0.500^{* * * *} \\
(0.023)\end{array}$ & & & & & $\begin{array}{c}0.452^{* * *} \\
(0.023)\end{array}$ & \\
\hline MNC & & & & & $\begin{array}{c}0.091^{* * *} \\
(0.009)\end{array}$ & & & & & $\begin{array}{c}0.095^{* * *} \\
(0.009)\end{array}$ \\
\hline MNC $\times$ Dummy & & & & & $\begin{array}{c}-0.025^{*} \\
(0.013)\end{array}$ & & & & & $\begin{array}{l}-0.016 \\
(0.013) \\
\end{array}$ \\
\hline Year fixed effect & yes & yes & yes & yes & yes & yes & yes & yes & yes & yes \\
\hline Product-destination fixed effect & yes & yes & yes & yes & yes & yes & yes & yes & yes & yes \\
\hline Observations & 2809014 & 2809014 & 2809014 & 694968 & 825963 & 2664724 & 2664724 & 2664724 & 656417 & 791670 \\
\hline Adjusted $R^{2}$ & 0.570 & 0.569 & 0.571 & 0.624 & 0.525 & 0.564 & 0.563 & 0.565 & 0.622 & 0.520 \\
\hline
\end{tabular}

Notes: Cluster-robust standard errors in parentheses, clustered by HS-4 product-destination. All regressions include a constant term.

***, **, and * indicate significance at the $1 \%, 5 \%$, and $10 \%$ level. Using ExtFin computed by Chinese data does not alter the results in this table. 
Table 12: Robustness: Credit Constraints and Export Prices (with Processing Trade)

\begin{tabular}{|c|c|c|c|c|c|}
\hline Regressor: & (1) & $(2)$ & (3) & $(4)$ & (5) \\
\hline \multirow[t]{2}{*}{$\log (\mathrm{TFP})$} & $0.094^{* * *}$ & $0.092^{* * *}$ & $0.093^{* * *}$ & $0.038^{* * *}$ & $0.091^{* * *}$ \\
\hline & $(0.003)$ & $(0.003)$ & $(0.003)$ & $(0.004)$ & $(0.005)$ \\
\hline \multirow[t]{2}{*}{$\log ($ Labor $)$} & $0.044^{* * *}$ & $0.044^{* * *}$ & $0.041^{* * *}$ & $-0.010^{* * *}$ & $0.036^{* * *}$ \\
\hline & $(0.002)$ & $(0.002)$ & $(0.002)$ & $(0.003)$ & $(0.005)$ \\
\hline \multirow[t]{2}{*}{$\log$ (Capitla/Labor) } & $0.067^{* * *}$ & $0.066^{* * *}$ & $0.069^{* * *}$ & $0.028^{* * *}$ & $0.076^{* * *}$ \\
\hline & $(0.002)$ & $(0.002)$ & $(0.002)$ & $(0.003)$ & $(0.003)$ \\
\hline \multirow[t]{2}{*}{$\log$ (Wage) } & $0.296^{* * *}$ & $0.317^{* * *}$ & $0.293^{* * *}$ & $0.182^{* * *}$ & $0.378^{* * *}$ \\
\hline & $(0.005)$ & $(0.005)$ & $(0.005)$ & $(0.006)$ & $(0.008)$ \\
\hline \multirow[t]{2}{*}{ ExtFin } & $-3.148^{* * *}$ & $-3.175^{* * *}$ & $-3.131^{* * *}$ & $-3.965^{* * *}$ & $-3.187^{* * *}$ \\
\hline & $(0.325)$ & $(0.326)$ & $(0.325)$ & $(0.404)$ & $(0.379)$ \\
\hline \multirow[t]{2}{*}{ All Credits to GDP Ratio } & $0.345^{* * *}$ & & & & \\
\hline & $(0.008)$ & & & & \\
\hline \multirow[t]{2}{*}{ Short-term Loans to GDP Ratio } & & $0.654^{* * *}$ & & & \\
\hline & & $(0.025)$ & & & \\
\hline \multirow[t]{2}{*}{ Long-term Loans to GDP Ratio } & & & $0.588^{* * *}$ & & \\
\hline & & & $(0.013)$ & & \\
\hline \multirow[t]{2}{*}{ SOE } & & & & $0.256^{* * *}$ & \\
\hline & & & & $(0.016)$ & \\
\hline \multirow[t]{2}{*}{$\mathrm{MNC}$} & & & & & $0.047^{* * *}$ \\
\hline & & & & & $(0.007)$ \\
\hline Year fixed effect & yes & yes & yes & yes & yes \\
\hline Product-destination fixed effect & yes & yes & yes & yes & yes \\
\hline Observations & 4092595 & 4092595 & 4092595 & 757980 & 1312308 \\
\hline Adjusted $R^{2}$ & 0.561 & 0.560 & 0.561 & 0.630 & 0.529 \\
\hline
\end{tabular}

Notes: Cluster-robust standard errors in parentheses, clustered by HS-4

product-destination. All regressions include a constant term.

$* * *,{ }^{* *}$, and ${ }^{*}$ indicate significance at the $1 \%, 5 \%$, and $10 \%$ level.

Using ExtFin computed by Chinese data does not alter the results in this table. 
Table 13: Robustness: Credit Constraints and Export Prices (with Labor Productivity or without Controlling for TFP)

\begin{tabular}{|c|c|c|c|c|c|c|c|c|c|c|}
\hline \multirow[b]{2}{*}{ Regressor: } & \multicolumn{5}{|c|}{ Labor Productivity } & \multicolumn{5}{|c|}{ No TFP } \\
\hline & (1) & (2) & (3) & (4) & (5) & (6) & (7) & (8) & (9) & (10) \\
\hline \multirow[t]{2}{*}{$\log (\mathrm{TFP})$} & $0.077^{* * *}$ & $0.075^{* * *}$ & $0.075^{* * *}$ & $0.052^{* * *}$ & $0.093^{* * *}$ & & & & & \\
\hline & $(0.002)$ & $(0.002)$ & $(0.002)$ & $(0.004)$ & $(0.004)$ & & & & & \\
\hline \multirow[t]{2}{*}{$\log$ (Labor) } & $0.042^{* * *}$ & $0.039^{* * *}$ & $0.041^{* * *}$ & $-0.011^{* * *}$ & $0.028^{* * *}$ & $0.037^{* * *}$ & $0.034^{* * *}$ & $0.036^{* * *}$ & $-0.015^{* * *}$ & $0.023^{* * *}$ \\
\hline & $(0.002)$ & $(0.002)$ & $(0.002)$ & $(0.003)$ & $(0.004)$ & $(0.002)$ & $(0.002)$ & $(0.002)$ & $(0.003)$ & $(0.004)$ \\
\hline \multirow[t]{2}{*}{ log(Capitla/Labor) } & $0.023^{* * *}$ & $0.024^{* * *}$ & $0.025^{* * *}$ & $0.007^{* *}$ & $0.025^{* * *}$ & $0.042^{* * *}$ & $0.043^{* * *}$ & $0.044^{* * *}$ & $0.019^{* * *}$ & $0.049^{* * *}$ \\
\hline & $(0.002)$ & $(0.002)$ & $(0.002)$ & $(0.003)$ & $(0.003)$ & $(0.002)$ & $(0.002)$ & $(0.002)$ & $(0.003)$ & $(0.003)$ \\
\hline \multirow[t]{2}{*}{ log(Wage) } & $0.240^{* * *}$ & $0.266^{* * *}$ & $0.234^{* * *}$ & $0.154^{* * *}$ & $0.294^{* * *}$ & $0.284^{* * *}$ & $0.308^{* * *}$ & $0.277^{* * *}$ & $0.180^{* * *}$ & $0.350^{* * *}$ \\
\hline & $(0.005)$ & $(0.005)$ & $(0.005)$ & $(0.006)$ & $(0.007)$ & $(0.006)$ & $(0.006)$ & $(0.005)$ & $(0.006)$ & $(0.008)$ \\
\hline \multirow[t]{2}{*}{ Extfin } & $-3.464^{* * *}$ & $-3.483^{* * *}$ & $-3.443^{* * *}$ & $-3.990^{* * *}$ & $-2.958^{* * *}$ & $-3.475^{* * *}$ & $-3.491^{* * *}$ & $-3.455^{* * *}$ & $-4.003^{* * *}$ & $-2.978^{* * *}$ \\
\hline & $(0.339)$ & $(0.340)$ & $(0.339)$ & $(0.400)$ & $(0.335)$ & $(0.341)$ & $(0.342)$ & $(0.341)$ & $(0.402)$ & $(0.335)$ \\
\hline \multirow[t]{2}{*}{ All Credits to GDP Ratio } & $0.305^{* * *}$ & & & & & $0.289^{* * *}$ & & & & \\
\hline & $(0.007)$ & & & & & $(0.007)$ & & & & \\
\hline \multirow[t]{2}{*}{ Short-term Loans to GDP Ratio } & & $0.412^{* * *}$ & & & & & $0.358^{* * *}$ & & & \\
\hline & & $(0.019)$ & & & & & $(0.019)$ & & & \\
\hline \multirow[t]{2}{*}{ Long-term Loans to GDP Ratio } & & & $0.560^{* * *}$ & & & & & $0.541^{* * *}$ & & \\
\hline & & & $(0.011)$ & & & & & $(0.011)$ & & \\
\hline \multirow[t]{2}{*}{ SOE } & & & & $0.274^{* * *}$ & & & & & $0.256^{* * *}$ & \\
\hline & & & & $(0.016)$ & & & & & $(0.016)$ & \\
\hline \multirow[t]{2}{*}{ MNC } & & & & & $0.078^{* * *}$ & & & & & $0.072^{* * *}$ \\
\hline & & & & & $(0.007)$ & & & & & $(0.007)$ \\
\hline Year fixed effect & yes & yes & yes & yes & yes & yes & yes & yes & yes & yes \\
\hline Product-destination fixed effect & yes & yes & yes & yes & yes & yes & yes & yes & yes & yes \\
\hline constant & yes & yes & yes & yes & yes & yes & yes & yes & yes & yes \\
\hline Observations & 2809014 & 2809014 & 2809014 & 694968 & 825963 & 2809014 & 2809014 & 2809014 & 694968 & 825963 \\
\hline Adjusted $R^{2}$ & 0.570 & 0.569 & 0.571 & 0.623 & 0.525 & 0.569 & 0.568 & 0.570 & 0.623 & 0.524 \\
\hline
\end{tabular}

Notes: Cluster-robust standard errors in parentheses, clustered by HS-4 product-destination. All regressions include a constant term.

${ }^{* * *},{ }^{* *}$, and ${ }^{*}$ indicate significance at the $1 \%, 5 \%$, and $10 \%$ level. Using ExtFin computed by Chinese data does not alter the results in this table. 
Table 14: Robustness: Credit Constraints and Export Prices (with TFP Computed by ACF (LP and OP) Method)

\begin{tabular}{|c|c|c|c|c|c|c|c|c|c|c|}
\hline \multirow[b]{2}{*}{ Regressor: } & \multicolumn{5}{|c|}{ LP embedded ACF } & \multicolumn{5}{|c|}{ OP embedded ACF } \\
\hline & (1) & (2) & (3) & (4) & (5) & (6) & (7) & (8) & (9) & (10) \\
\hline \multirow[t]{2}{*}{$\log (\mathrm{TFP})$} & $0.022^{* * *}$ & $0.019^{* * *}$ & $0.021^{* * *}$ & 0.003 & $0.055^{* * *}$ & $0.0306^{* * *}$ & $0.028^{* * *}$ & $0.030^{* * *}$ & $0.019^{* * *}$ & $0.062^{* * *}$ \\
\hline & $(0.002)$ & $(0.002)$ & $(0.002)$ & $(0.004)$ & $(0.004)$ & $(0.002)$ & $(0.002)$ & $(0.002)$ & $(0.003)$ & $(0.004)$ \\
\hline \multirow[t]{2}{*}{$\log ($ Labor $)$} & $0.036^{* * *}$ & $0.033^{* * *}$ & $0.035^{* * *}$ & $-0.015^{* * *}$ & $0.019^{* * *}$ & $0.0337^{* * *}$ & $0.031^{* * *}$ & $0.033^{* * *}$ & $-0.018^{* * *}$ & $0.015^{* * *}$ \\
\hline & $(0.002)$ & $(0.002)$ & $(0.002)$ & $(0.003)$ & $(0.004)$ & $(0.002)$ & $(0.002)$ & $(0.002)$ & $(0.003)$ & $(0.004)$ \\
\hline \multirow[t]{2}{*}{$\log$ (Capitla/Labor) } & $0.043^{* * *}$ & $0.043^{* * *}$ & $0.044^{* * *}$ & $0.019^{* * *}$ & $0.050^{* * *}$ & $0.0469^{* * *}$ & $0.047^{* * *}$ & $0.048^{* * *}$ & $0.022^{* * *}$ & $0.058^{* * *}$ \\
\hline & $(0.002)$ & $(0.002)$ & $(0.002)$ & $(0.003)$ & $(0.003)$ & $(0.002)$ & $(0.002)$ & $(0.002)$ & $(0.003)$ & $(0.003)$ \\
\hline \multirow[t]{2}{*}{$\log ($ Wage $)$} & $0.273^{* * *}$ & $0.299^{* * *}$ & $0.267^{* * *}$ & $0.179^{* * *}$ & $0.321^{* * *}$ & $0.269^{* * *}$ & $0.294^{* * *}$ & $0.262^{* * *}$ & $0.171^{* * *}$ & $0.317^{* * *}$ \\
\hline & $(0.005)$ & $(0.006)$ & $(0.005)$ & $(0.006)$ & $(0.008)$ & $(0.005)$ & $(0.005)$ & $(0.005)$ & $(0.006)$ & $(0.008)$ \\
\hline \multirow[t]{2}{*}{ Extfin } & $-3.472^{* * *}$ & $-3.489^{* * *}$ & $-3.452^{* * *}$ & $-4.002^{* * *}$ & $-2.973^{* * *}$ & $-3.467^{* * *}$ & $-3.486^{* * *}$ & $-3.447^{* * *}$ & $-3.996^{* * *}$ & $-2.966^{* * *}$ \\
\hline & $(0.341)$ & $(0.342)$ & $(0.341)$ & $(0.402)$ & $(0.336)$ & $(0.341)$ & $(0.341)$ & $(0.341)$ & $(0.402)$ & $(0.336)$ \\
\hline \multirow[t]{2}{*}{ All Credits to GDP Ratio } & $0.294^{* * *}$ & & & & & $0.296^{* * *}$ & & & & \\
\hline & $(0.007)$ & & & & & $(0.007)$ & & & & \\
\hline \multirow[t]{2}{*}{ Short-term Loans to GDP Ratio } & & $0.370^{* * *}$ & & & & & $0.378^{* * *}$ & & & \\
\hline & & $(0.019)$ & & & & & $(0.019)$ & & & \\
\hline \multirow[t]{2}{*}{ Long-term Loans to GDP Ratio } & & & $0.548^{* * *}$ & & & & & $0.550^{* * *}$ & & \\
\hline & & & $(0.011)$ & & & & & $(0.011)$ & & \\
\hline \multirow[t]{2}{*}{ SOE } & & & & $0.257^{* * *}$ & & & & & $0.270^{* * *}$ & \\
\hline & & & & $(0.016)$ & & & & & $(0.016)$ & \\
\hline \multirow[t]{2}{*}{ MNC } & & & & & $0.079^{* * *}$ & & & & & $0.078^{* * *}$ \\
\hline & & & & & $(0.007)$ & & & & & $(0.007)$ \\
\hline Year fixed effect & yes & yes & yes & yes & yes & yes & yes & yes & yes & yes \\
\hline Product-destination fixed effect & yes & yes & yes & yes & yes & yes & yes & yes & yes & yes \\
\hline constant & yes & yes & yes & yes & yes & yes & yes & yes & yes & yes \\
\hline Observations & 2809014 & 2809014 & 2809014 & 694968 & 825963 & 2809014 & 2809014 & 2809014 & 694968 & 825963 \\
\hline Adjusted $R^{2}$ & 0.569 & 0.568 & 0.570 & 0.623 & 0.525 & 0.570 & 0.568 & 0.570 & 0.623 & 0.525 \\
\hline
\end{tabular}

Notes: Cluster-robust standard errors in parentheses, clustered by HS-4 product-destination. All regressions include a constant term.

${ }^{* * *},{ }^{* *}$, and ${ }^{*}$ indicate significance at the 1\%, 5\%, and 10\% level. Using ExtFin computed by Chinese data does not alter the results in this table. 